\title{
Technology and Epidemics
}

\section{ALBERTO CHONG and LUISA ZANFORLIN*}

Evidence from historical and epidemiological literatures shows that epidemics tend to spread in the population according to a logistic pattern. We conjecture that the impact of new technologies on output follows a pattern of spread not unlike that of typical epidemics. After reaching a critical mass, rates of growth will accelerate until the marginal benefits of technology are fully utilized. We estimate spline functions using a GMM dynamic panel methodology for 79 countries. We use imports of machinery and equipment as a fraction of gross domestic product as a proxy for the process of technological adoption. Results confirm our hypothesis. [JEL O39, O40, O1]

A empirical regularity in the epidemiology literature is that the spread of infectious epidemics in the population tends to follow a logistic pattern. In the first stage, the rate of contagion is low, and thus the number of infected individuals remains relatively stable. The second stage occurs when a critical number of individuals become infected, so that once this threshold is reached, the rate of infection accelerates rapidly, and, consequently, the number of infected cases increases dramatically. In particular, Geoffard and Philipson (1995) explain that "the larger the fraction of infected people in the population, the larger the fraction of uninfected people who will become infected in the next period, since the

*Alberto Chong is a Senior Research Economist at the Research Department of the Inter-American Development Bank and an Adjunct Professor at Georgetown University Public Policy Institute. Luisa Zanforlin is an Economist in the European I Department of the International Monetary Fund. The authors are grateful to César Calderón, David T. Coe, Stanley Fischer, Virgilio Galdo, Natalia Pérez, Lant Pritchett, Robert Waldmann, anonymous referees, the editor, and seminar participants at the World Bank, the International Monetary Fund, Harvard University, and participants at the Latin American Econometric Society Meetings, for comments. Editorial comments by Sean Culhane and Thomas Walter are gratefully acknowledged. 
probability that a susceptible individual will meet an infected individual increases." In the third stage, the rate of infection will slow down and thus the number of infected cases will stabilize; epidemics tend to display a self-correcting character as the rising risk of infection causes potential victims to take self-protective measures (Philipson and Posner, 1996). Depending on, among other factors, the rate of growth of the population and new medical advances, infectious epidemics will either become endemic or eventually die out.

Plenty of historical examples display a logistic pattern similar to the one described above. For instance, this is the case with the numerous accounts of smallpox epidemics in England during the eighteenth century where, after initial low rates of infection and, hence, a limited number of cases, "spectacular outbreaks with widespread mortality followed," later to become stabilized and endemic for decades, in particular in rural areas (Duncan, Scott, and Duncan, 1993; Creighton, 1965). An example of an epidemic wiping out an entire population is the outbreak on the Island of Foula in 1720 where a smallpox epidemic left the town with only six inhabitants out of two hundred (Razzell, 1977). Other historical examples that have displayed a similar pattern are the bubonic plague and different kinds of influenza in Europe, and, in more contemporary times, cholera in several developing countries and even the spread of HIV in parts of Africa (Anderson and May, 1991; and United Nations, 1997). ${ }^{1}$

In economics, a logistic pattern has been empirically studied in some microeconomic relationships, in particular with respect to technology adoption in agriculture. This is the case of the seminal study on hybrid corn by Griliches (1957). Though some researchers have also hypothesized a macro link, to our knowledge, no empirical study of the sort has been done so far. At the macro level, we conjecture that the link between newly transferred technologies on output via imports of machinery and equipment roughly follows three analogous stages..$^{2}$ In a first stage, the introduction of technology new to the country may have little or no effect on growth rates and output. As in the case of an epidemic, a critical mass of technology or know-how may be required. Any new innovation may have limited impact on overall output if complementary technological developments are not in place. It may well occur that a new machine in the production line makes little or no impact on overall productivity unless all the equipment in the assembly line has also been upgraded. A new computer cannot improve the graphic quality of the printed document if the printer has not been replaced too. Other know-how complementarities are the need for additional training of the workforce, reorganization of the productive process, and the retirement and replacement of obsolete machinery.

\footnotetext{
${ }^{1}$ Notice that unlike infectious epidemics such as the plague, cholera, or smallpox, AIDS is a "rational" epidemic, in the sense that it is spread primarily by voluntary contact. As such, exposure to HIV may be avoided through the avoidance of such behavior. Consequently, the spread of AIDS is not expected to necessarily follow a logistic pattern (Geoffard and Philipson, 1996).

${ }^{2}$ Similar to De Long and Summers (1991) an implicit assumption is that technology is embodied in machinery. We focus on technology transfer through imports of machinery and equipment although the pattern we conjecture may also be applied to domestic technology. Lee (1995) uses cross-country data to show that the ratio of imported to domestically produced capital goods in the composition of investment has a significant positive effect on growth rates, in particular in developing countries.
} 
Thus, a recently acquired technology may require an "incubation" stage, a minimum accumulation of know-how necessary for optimal employment of the new technology. Thus, during this first stage, we would expect little change in the rates of growth and, consequently, in output (equivalent to the number of cases in epidemiology literature). ${ }^{3}$ In a second stage, it is expected that the impact of the newly acquired technology would become more apparent. The labor force has learned the functioning of the new equipment, new administrative and organizational procedures are in place, and the new machinery is optimally calibrated and performing smoothly. In this stage, we would expect growth rates to increase not only because of higher productivity owing to the introduction of technology, but also because of the potential domestic spillovers that are produced. The mastering of one specific technology may also benefit other related domestic industries. ${ }^{4}$ Thus, while growth accelerates, output is expected to rise dramatically. This stage is equivalent to the "high-rate-of-contagion" stage in the epidemiology literature. In a third stage, the technology becomes fully exploited, the marginal impact on growth rates decreases as the spillover effects decline, and output tends to stabilize.

The aim of this paper is to empirically investigate whether the impact of technologies embodied in the stock of imported machinery and equipment on output displays a logistic pattern similar to the spread of typical infectious epidemics in the population. We analyze this link by focusing on the slope of such a relationship. To do this, we use unrestricted and restricted spline functions. In a linearized epidemictype function the slope is expected to increase once a lower threshold is reached and then to decrease after a second threshold, or upper bound. ${ }^{5} \mathrm{We}$ focus on flows and thus estimate standard growth specifications that use imports of equipment and machinery as our variable of interest. In order to control for heterogeneity and endogeneity in the regressors, we use a Generalized Method of Moments (GMM) approach for dynamic panel data, along the lines of Arellano and Bover (1995) and others, and we apply Sargan tests and serial correlation tests to check for the validity of the instruments. We find robust, statistically significant differences in the technology coefficients that are consistent with the "stages" of an infectious epidemic, as described above. Technology embodied in imports of machinery and equipment appears to have an impact on output consistent with a logistic function.

\section{Brief Review of the Literature}

As in the case of typical infectious epidemics, the idea that there may be an "incubation" stage followed by a "high-rate-of-contagion" stage once a critical mass is reached somewhat resembles the theoretical work on thresholds by Azariadis and

\footnotetext{
${ }^{3}$ In his well-known analogy between the diffusion of electricity and computers, David (1990) argues that factory electrification did not have an impact on productivity growth in manufacturing before the 1920 s, even though this was four decades after the first central power station opened for business.

${ }^{4}$ Microchips are a typical example. If production is mastered domestically after the new technology is first imported, this may also benefit other local manufacturers who need microchips to produce their own products and/or manufacturers who use a technology that shares an analogous principle.

${ }^{5} \mathrm{Or}$, at least, to increase at much lower rates.
} 
Drazen (1990). They argue that, if an economy reaches a critical mass of technology, the rate of growth will accelerate and the economy will move from one locally stable, low-growth equilibrium to another with higher growth rates. Threshold effects owing to technological externalities will give rise to "radical differences in dynamic behavior," and the economy will shift in a stepwise pattern along a series of locally stable equilibria. The technological externalities that Azariadis and Drazen consider are typically spillovers from the stocks of capital and increases in labor quality owing to training, along the lines of the endogenous growth literature. The more you invest, the higher the social returns arising from the externalities.

Our approach somewhat resembles that of Azariadis and Drazen. We conjecture that the diffusion of technology through imports of equipment produces an accumulation of know-how up to a critical mass, which gives rise to an acceleration in the growth rates and augments the production possibilities of the economy. However, we view the accumulation of technology as endogenous to the dynamics of the system, and thus assume that technology is "infectious" just like a disease. Additionally, the diffusion of technology allows an economy to "catch up" by importing equipment already available in other countries, which is technologically advanced relative to the knowledge in the local economy. Once this technological absorption is complete, the impact of imported equipment on growth and output will tend to die out. That is, once a technology has been diffused throughout the system, the rate of growth of the economy will tend to stabilize over the long-run rate in the same way that, after an epidemic has been diffused, the rate of new contagion will be determined mainly by the rate of growth of the population.

Empirical work along these lines has been pursued by Levin and Raut (1997), who, in exploring the issue of the time devoted to "preparation and learning," show that training is necessary for foreign technology to be efficiently adopted. They explain how this process requires more specialized human capital. In particular, they use a panel of 30 semi-industrialized developing nations between 1965 and 1984 to explore the evidence on policies that stimulate long-run growth by simultaneously promoting investment in human capital and in the manufacturing export sector, on the assumption of complementarity between exports and education expenditures. According to these authors, "educated workers may be able to adapt more quickly to the sophisticated technology and rapid production changes required for competitiveness in the world markets" (p. 166).

Similarly, Goldin and Katz (1998) study the origins of technology-skill complementarity in manufacturing in the United States. They offer evidence of the existence of technology-skill and capital-skill (relative) complementarities from 1909 to 1929, and suggest that they are associated with "continuous-process and batch methods and the adoption of electric motors." Goldin and Katz find evidence that industries that used more capital per worker and a greater proportion of their horsepower in the form of purchased electricity employed more educated bluecollar workers in 1940 and paid their blue-collar workers substantially more from 1909 to 1929. Finally, Temple (1998) argues, though does not prove, that when a new technology is adopted it requires investment in training and reorganization, as well as in machinery; in addition, De Long and Summers (1991 and 1993) and Lee 
(1995) emphasize the plausibility of the hypothesis that equipment investment is a key mechanism of technology transfer and argue that the effect of equipment on growth may be smaller for rich than for poor countries.

\section{Some Simple Theoretical Motivation}

Our hypothesis is that output follows an epidemic-type pattern with respect to the recently acquired foreign technologies typically embodied in imported machinery and equipment. In other words, we postulate that the relationship between a country's GDP, $Y^{i}$, and the stock of technology or know-how in a country, $T$, resembles the pattern of a logistic function (Gomulka, 1990; Davies, 1979):

$$
Y_{T}^{i}=\frac{Y_{R}}{1-e^{-\alpha-\gamma T}},
$$

where $Y_{R}$ is an upper bound, or maximum possible achievable output, determined by the stock of available technology in the world, $T_{w}$, such that:

$$
\lim _{T \rightarrow \infty^{+}} Y_{T}^{i}=Y_{T_{W}}^{i}=Y_{R} .
$$

Both $\gamma$ and $\alpha$ are parameters greater than zero. The first gives the speed of adjustment (i.e., the slope) of the process, and the second ensures that, in the absence of technology acquisition, the output will still be positive:

$$
\lim _{T \rightarrow 0} Y_{T}^{i}=\frac{Y_{R}}{1-e^{-\alpha}}>0
$$

By rearranging equation (1) and taking first differences with respect to the stock of technology available in the country, we obtain:

$$
\frac{Y_{T}^{i}}{Y_{R}}=\frac{1}{1-e^{-\alpha-\gamma T}},
$$

or

$$
\Delta \frac{Y^{i}}{Y_{R}}=\gamma \frac{Y^{i}}{Y_{R}}\left[1-\frac{Y^{i}}{Y_{R}}\right] \Delta T
$$

With no loss of generality, we define $\gamma=\lambda Y_{R}$, so that: 


$$
\Delta Y^{i}=\lambda Y^{i}\left[Y_{R}-Y^{i}\right] \Delta T
$$

The expression above links change in technological stock and change in output. If we define $\theta \equiv \lambda Y^{i}\left[Y_{R}-Y^{i}\right]$ it becomes clear that the shape of equation (6) is not constant but concave. A logistic relationship between technology and output yields a nonmonotonic, concave relationship between change in output and change in technology stock. This is useful in terms of our empirical approach, as equation (6) indicates that the link between output and technology may be estimated using growth equations (change in output) with the coefficient of the proxy for change in technological stock, $\theta$ (imports of machinery and equipment), not being constant.

\section{Data and Empirical Strategy}

We use data for 79 countries for the period from 1960 to 1995 (see Appendix I). We construct a five-year period panel (1960-65, 1965-70, 1970-75, 1975-80, 1980-85, 1985-90, and 1990-95), estimate standard log-linear growth regressions, and focus on the coefficient of our technology proxy, which yields the slope of the output-technology relationship, as shown in the previous section. Our basic empirical specification follows the lines of De Long and Summers (1991 and 1993), Lee (1995), and Temple (1998), and has the form:

$$
G R W=\rho+\delta L G A P_{t}+\omega S C H L_{t}+\theta I M E Q_{t}+\beta O I N V_{t}+\eta L A B G_{t}+\varepsilon_{t},
$$

where the dependent variable, $G R W$, is the real per capita GDP growth rate and is constructed as the difference of the log values of per capita GDP averaged over each period. $L G A P$ is the natural logarithm of the ratio of a country's per capita GDP to the per capita GDP of the United States; consequently this "initial condition" coefficient represents the speed of the catching-up process with respect to the technology frontier, as argued by De Long and Summers (1991 and 1993). SCHL represents the average years of schooling in the population (Barro and Lee, 1993). $L A B G$ is the rate of growth of the labor force, proxied by the average growth rate of the population.

The sources of the above variables are Barro and Lee (1993), The Penn World Tables, Mark 5.6 (Summers and Heston, 1991), and the World Bank (1997). Also, along the lines of De Long and Summers (1991) and Temple (1998), we include the variable $O I N V$, or investment other than imports of equipment, as a share of GDP. The data for imports of machinery and equipment (IMEQ), our variable of interest, were taken from the United Nations' International Trade Statistics Yearbook and from the Bulletin of Statistics on World Trade in Engineering Products corresponding to Section 7, "machinery and transport equipment," of the 
SITC classification. ${ }^{6}$ We construct this variable as the share of imported machinery and equipment to gross domestic product.

We believe that IMEQ appropriately captures the acquisition of foreign technologies by countries. Evidence shows that the production of machinery and equipment is an industry in which research and development expenditures are higher than in other industries, and in which a larger share of patents is awarded (Coe and Helpman, 1995; Guerrieri, 1992; Patel and Pavitt, 1990; and Soete, 1987). Imports of machinery and equipment are regarded as vehicles through which technology is transferred across countries. The above arguments are particularly relevant, given that our sample starts in 1960, when the adoption of foreign technologies was mainly concentrated among what are currently semi-industrial and industrial countries. Also, while total investment in equipment captures domestic and already adopted technologies in a country, it should be noted that recently available foreign technologies will be better represented by considering imported equipment and machinery. ${ }^{7}$

Given that the coefficient on imported machinery and equipment yields the slope of the output-technology relationship, the idea is to uncover whether, depending on the technological stage of the country, there may be statistically significant differences in the corresponding coefficients. Consistent with the simple model presented in the previous section, it is expected that, if an epidemictype pattern exists, the coefficients of our variable of interest will increase after a threshold point is reached and later decrease, once a second threshold has been reached. We use three complementary approaches based on the basic prediction in our simple model, that is, that the coefficient on imports of machinery and equipment in our benchmark growth regression displays a nonmonotonic pattern in an epidemic-type relationship between technology and output.

\section{Interval Location Approach}

Although, strictly speaking, we do not need to identify the exact location of the supposed thresholds in order to search for the existence of nonlinearities, we first use a very simple method that helps us locate the most likely intervals along the range of IMEQ values consistent with the possible "incubation" (initial), "highrate-of-contagion" (middle), and "dying-out" (last) stages, similar to those typical of infectious epidemics. We apply a simple empirical strategy to find these possible nonlinearities in our variable of interest. Using the benchmark specifica-

\footnotetext{
${ }^{6}$ Section 7 of the Standard International Trade Classification (SITC) includes all kinds of machinery and parts. The main subcategories are electrical and nonelectrical machinery and transport equipment. Electrical machinery comprises electric power generators, domestic electrical appliances, medical appliances, telecommunications equipment, office machinery, and others. Nonelectrical machinery includes nuclear reactors and power generators other than electric, and machinery for special industries such as agricultural, textile, and printing machinery etc. We also used a narrow definition by excluding transport equipment and obtained similar results (see results section, below).

${ }^{7}$ In De Long and Summers (1993), the authors use imports of equipment as a proxy of total investment of equipment for 30.1 percent of their sample (27 countries out of 88).
} 
tion in equation (7), we run spline regressions using a dummy variable. The dummy is used to uncover the path in the coefficient of our variable of interest. To do so, multiple regressions are estimated by changing the initial value of the dummy in a systematic fashion along the range of IMEQ values. We expect that the path of slopes estimated from the set of regressions with these splines will give an indication where structural changes might be occurring on the slope of the coefficient of IMEQ; in turn, this will give an idea of the location and size of the three hypothesized intervals, if they exist at all. The result of the spline regression is two slopes: one that covers the range from the origin to the assigned location of the spline; the other from that point to the highest IMEQ value observed.

If there were no structural break in the coefficients for IMEQ, there would not be a statistically significant difference among the coefficients of the two slopes. However, if the pattern estimated were consistent with the first stage of a typical epidemic, the regression coefficient would be statistically nonsignificant in the initial intervals along the range of IMEQ values: in the incubation stage, the slope of the technology-output relationship tends to be zero. If the initial point of the dummy variable is moved along the range of IMEQ values, the regression coefficient, to be consistent with the second stage of an epidemic pattern, should become both increasingly positive and statistically significant. At a certain point, the regression coefficient (slope) is expected to peak. This would signal the beginning of the third, dying-out stage. At this stage, the coefficients estimated on the initial interval are expected to be smaller. The expected path of slopes obtained by systematically estimating the regression with increasing initial points for the dummies can be seen if Figure 1 is linearized by using two segments of different lengths. By using this simple method, we expect to find the hypothesized threestage epidemic pattern with reasonable accuracy.

\section{Unrestricted Approach}

Based on the likely thresholds identified in the previous approach, we use a second simple method to further check whether the nonlinearities in our growth relationship are consistent with those of an epidemic-type function. We run growth regressions for each of the identified intervals independently and contrast the estimated coefficients with the ones for the full sample. We test whether the signs and significance of the coefficients of the subsamples are different from those of the coefficient for the full sample, as would be expected. For instance, in the case of the middle interval, we expect the IMEQ coefficient of the corresponding subsample to be significantly greater than the coefficient for the full sample. Similarly, we expect the coefficient of the first interval (incubation stage) to be statistically nonsignificant, and the coefficient of the third interval (dying-out stage) to be also close to zero.

Additionally, we trace the local path of the IMEQ coefficient in order to check for consistency. We do this by changing the size of the identified middle, or highrate-of-contagion interval and re-estimating the resulting coefficients. In particular, we fix the lower threshold of the originally identified middle interval and increase the upper bound. It is expected that on wider intervals the coefficients on 
Figure 1. Stock of Technology and Output

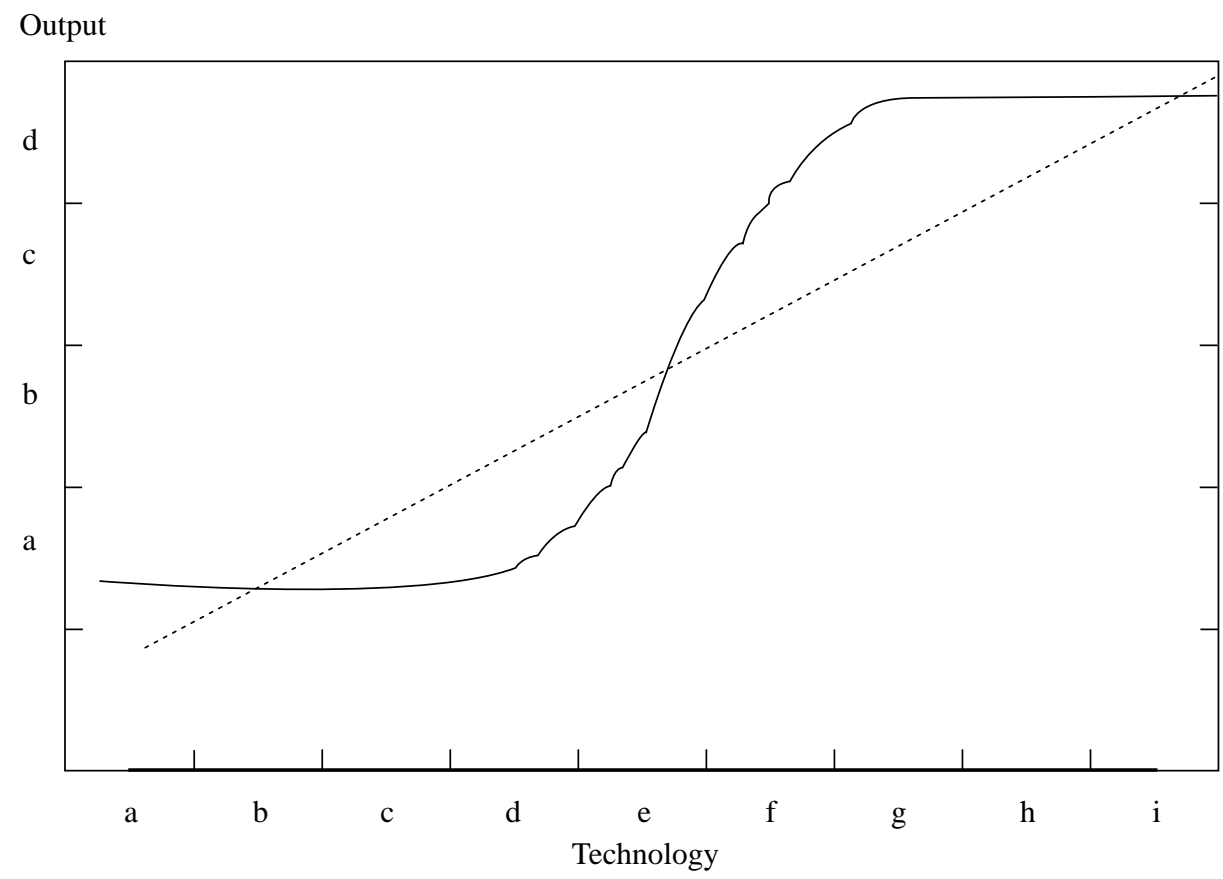

IMEQ will become smaller. Consistent with an epidemic-type relationship between technology and output, the slope of this wider interval is expected to decline. ${ }^{8}$ We repeat this procedure by fixing the upper threshold of our original middle interval and by decreasing the value of the lower threshold. We also expect the IMEQ coefficient to decline in this case, consistent with the basic prediction of our simple theoretical model. For both of the outer intervals (i.e., the interval from the higher threshold of the identified middle interval to the maximum possible IMEQ value, and the interval from the lower threshold of our identified middle interval to zero), we still expect that, if an epidemic-type pattern is present, the coefficients on IMEQ will be nonsignificant or at least significantly smaller than the estimates on the middle interval.

Figure 1 illustrates this simple procedure. We use a middle interval that approaches the high-rate-of-contagion stage, such as $[d, f]$, which is chosen by using the interval location approach explained in the previous subsection. The slope of this interval has to be higher than that of the full sample $[a, i]$ for it to be consistent with an epidemic pattern. Fixing the lower bound $d$ and increasing the size of the original interval by raising the upper bound from $f$ to $g$ is expected to yield a lower slope for the interval $[d, g]$ than for $[d, f]$. Consistent with the simple

\footnotetext{
${ }^{8}$ Since in every iteration we increase the extreme bounds of the initially identified interval by small values of IMEQ, we expect to find changes in the coefficient, although not necessarily statistically significant ones. However, the observed tendency in the path of the estimated slopes seems to be unambiguous.
} 
theoretical model, the wider the interval, the lower the slope. The result is analogous to fixing the upper threshold $f$ and increasing the size of the interval from $d$ to $c$. Moreover, the slopes of the incubation interval $[a, d]$ and that of the dyingout stage $[f, i]$ are both expected to be close to zero, or nonsignificant.

\section{Restricted Approach}

Because under the unrestricted approach samples are changed from estimation to estimation, such a methodology allows for every other coefficient besides IMEQ to change as well. However, this might not necessarily be an appropriate methodology for testing for a nonlinear structure within the growth specification of equation (7) because of the possibility of sample selection biases. Therefore, we also use a third approach: a simple restricted approach in which we employ spline functions that take into account the full sample in all the regressions and thus avoid the problem of selection bias. We simply place two dummy variables where we believe the beginning and end of the "high-rate-of-contagion" thresholds are, according to our interval location approach findings (above). We also perform local consistency checks by changing the size of the intervals.

\section{Econometric Methodology}

We take advantage of recent GMM dynamic panel data techniques to address potential endogeneity problems, as well as possible unobserved time and countryspecific effects that may produce biased and inconsistent estimates. ${ }^{9}$ The main technique applied follows the work of Arellano and Bond (1991) and Arellano and Bover (1995); the technique is briefly summarized in Appendix II (Calderón, Chong, and Loayza, 2002). This estimator employs jointly the regression equation in both differences and levels, each with its specific set of instrumental variables. It is called the GMM "system estimator" to underline its characteristic of joining in a single system level and difference specifications. However, ordinary least squared (OLS) estimates are also reported to allow for comparisons. The coefficients estimated when using the two techniques never diverge substantially.

\section{Results}

Table 1 presents basic summary statistics. On average, the East Asian and Pacific economies have the highest ratio of imports of machinery and equipment to GDP

\footnotetext{
${ }^{9}$ For instance, Alonso-Borrego and Arellano (1999), Arellano and Bond, (1991), Arellano and Bover (1995), Blundell and Bond (1997), Holtz-Eakin, Newey, and Rosen (1988), Kiviet (1995), and Ziliak (1997). These two issues, and in particular the first one, have dominated the discussion on trade and growth in recent years. Frankel and Romer (1996), Frankel, Romer, and Cyrus (1996), and Harrison (1996) provide literature reviews. Chong and Zanforlin (2001) and Calderón, Chong, and Zanforlin (2001) apply dynamic panel methods to the link between trade and growth.
} 
for the period 1960-95. It may be somewhat surprising that this ratio is higher than the corresponding ratio for the OECD countries in our sample ( 9.19 percent for OECD countries, 9.53 percent for East Asia), but it makes sense given that some highly industrialized countries, such as the United States and the United Kingdom, tend to have more domestic research and development and local investment and thus display relatively low IMEQ ratios. Even though there is a slightly positive simple correlation between average per capita growth and average IMEQ (0.06), it is not clear that the regions with the higher import ratios are also the regions that grow faster. While this is true if one compares East Asia and Pacific and OECD, such is not the general case. While the IMEQ ratio for South Asia is 2.39 percent, its average rate of growth is 2.68 percent. This contrasts sharply with Latin America, where the average IMEQ ratio was 4.29 percent of GDP, but the average growth rate was only 1.10 percent. This very simple first look at the data appears to give some general indication of possible nonlinearities in the relationship between the technology proxy, IMEQ, and growth, as can be seen in Figures 2 to 4 .

We present simple scatterplots of these two variables for the period 1960-95 for arbitrary intervals along the IMEQ range of values. The three intervals employed, [0.00-0.07], [0.07-0.15], and [0.15-0.50], correspond to Figures 2, 3, and 4, respectively. ${ }^{10}$ The differences are quite dramatic. While the simple correlation in the first interval is 0.001 , the correlation increases to about 0.11 for the second interval and

\begin{tabular}{|c|c|c|c|c|c|c|}
\hline \multicolumn{7}{|c|}{ Table 1. Summary Statistics, 1960-951 } \\
\hline & All & $\begin{array}{c}\text { Latin } \\
\text { America }\end{array}$ & $\begin{array}{l}\text { East Asia } \\
\text { Pacfic }\end{array}$ & OECD & $\begin{array}{l}\text { South } \\
\text { Asia }\end{array}$ & $\begin{array}{l}\text { Sub- } \\
\text { Saharan } \\
\text { Africa }\end{array}$ \\
\hline \multicolumn{7}{|l|}{$\begin{array}{l}\text { Imports of Machinery } \\
\text { and Equipment } \\
\text { (as a percent of GDP) }\end{array}$} \\
\hline Mean & 6.61 & 4.29 & 9.53 & 9.19 & 2.39 & 4.99 \\
\hline Standard deviation & 5.46 & 2.70 & 10.97 & 4.76 & 1.88 & 2.90 \\
\hline Maximum & 47.87 & 20.96 & 47.87 & 20.18 & 7.81 & 14.92 \\
\hline Minimum & 0.51 & 0.88 & 1.15 & 1.41 & 0.51 & 0.71 \\
\hline \multicolumn{7}{|l|}{$\begin{array}{l}\text { Annual GDP Per Capita } \\
\text { Growth Rate } \\
\text { (in percent) }\end{array}$} \\
\hline Mean & 2.00 & 1.10 & 3.64 & 2.53 & 2.68 & 0.72 \\
\hline Standard deviation & 2.85 & 3.06 & 3.14 & 1.54 & 2.23 & 3.00 \\
\hline Maximum & 10.98 & 7.97 & 9.69 & 6.48 & 7.51 & 8.59 \\
\hline Minimum & -5.83 & -5.69 & -4.14 & -0.43 & -2.18 & -5.83 \\
\hline
\end{tabular}

\footnotetext{
${ }^{10}$ Actually, the thresholds were chosen by using the interval location approach, as described above. See below in this same section for details.
} 


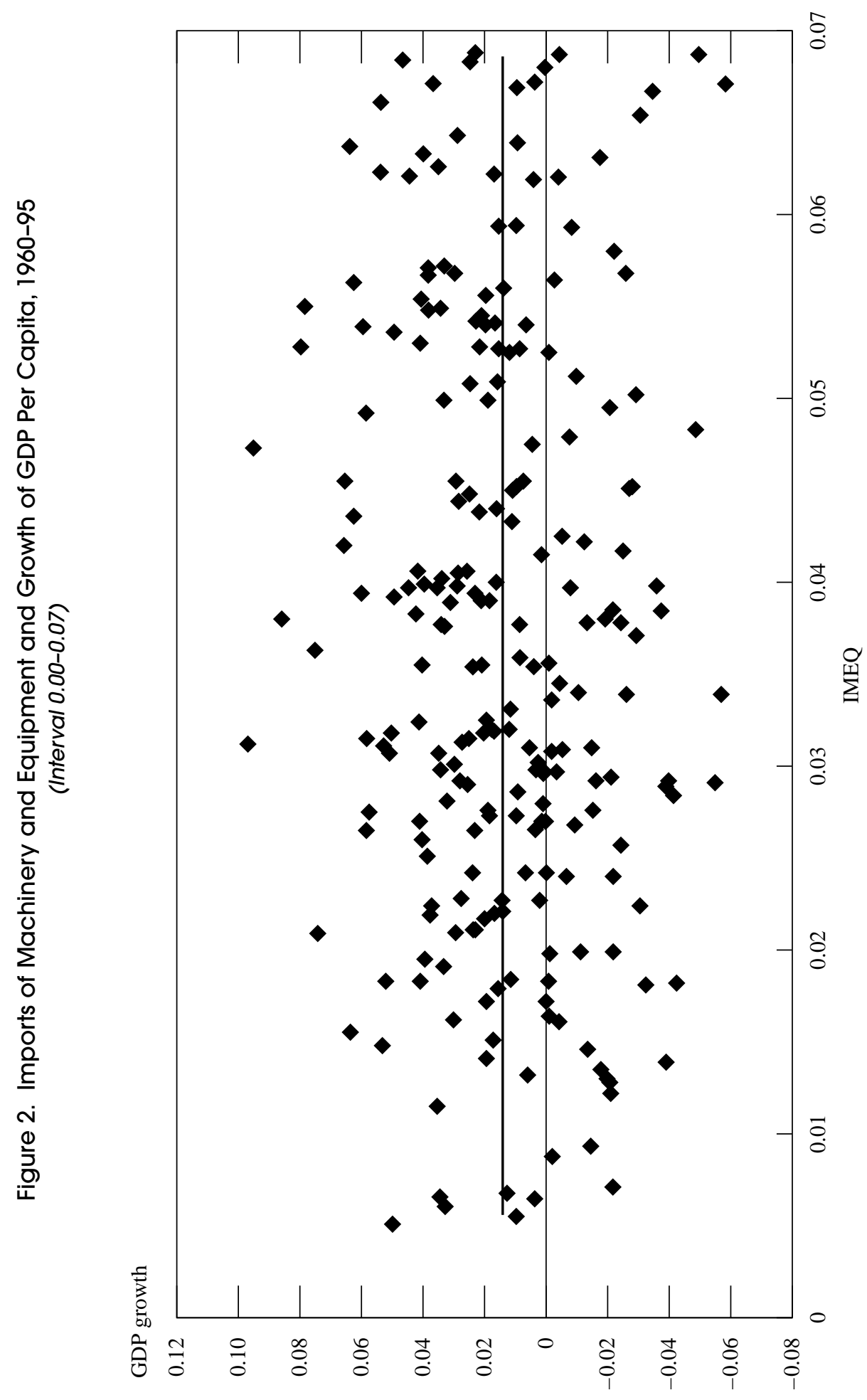


Alberto Chong and Luisa Zanforlin

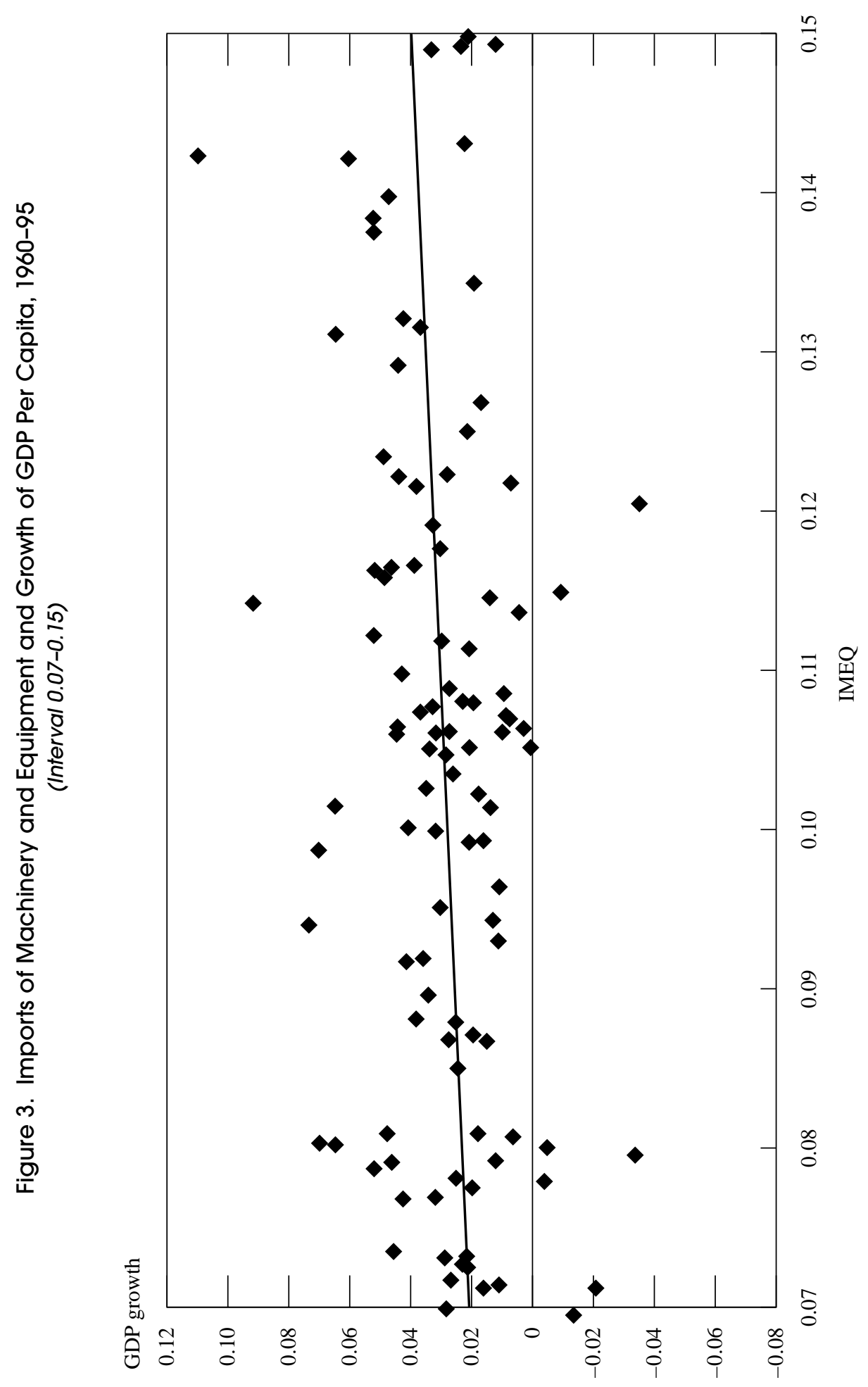


TECHNOLOGY AND EPIDEMICS

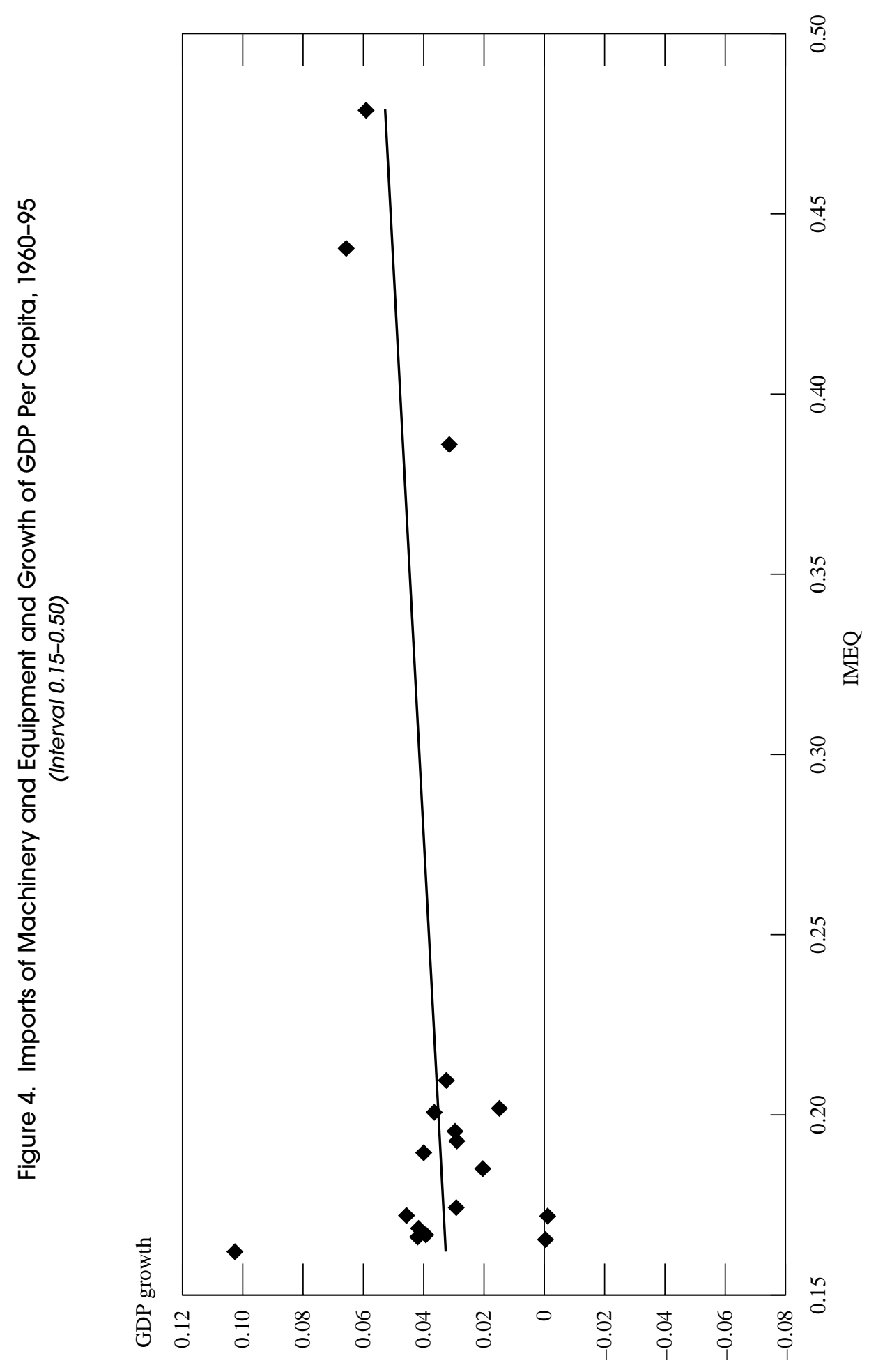


decreases to 0.06 for the third. This pattern is roughly consistent with the path of the slope of the technology proxy in an epidemic-type link between technology and output in its linearized form, as shown in Figure 1; the pattern observed in the three figures is also consistent with the three stages of infectious epidemics. ${ }^{11}$

Table 2 presents growth regressions for the full sample using our benchmark specification (equation 7). We use OLS along with the GMM system estimator method presented in Section V (below) to compare our estimates. All regressions include two-way fixed-effects methods. ${ }^{12}$ We also employ an alternative definition of our technology proxy that excludes the item "transport equipment" from Section 7 of the SITC on the grounds that, of the three categories comprising Section 7, transport equipment is sometimes regarded as the least likely to embody technology. ${ }^{13}$ The columns with asterisks report those findings. In general, the results are similar to other cross-country empirical research on growth. With respect to our variable of interest, IMEQ, we find that the coefficient is positive and statistically significant, at least at the 5 percent level, regardless of the econometric technique applied. The resulting coefficients are relatively stable. They fluctuate between 0.115 and 0.145 , numbers that are roughly consistent with previous findings by Temple (1998) and Lee (1995) for somewhat similar proxies. The estimates for the IMEQ coefficients are always higher when the more narrow definition is used. They are always positive and statistically significant. ${ }^{14}$ The rest of the tables show results using the same basic specification and the broader definition of IMEQ, our preferred proxy.

Tables 3 and 4 show our main findings when applying the simple interval location approach described in the empirical strategy section. ${ }^{15}$ As explained above, we add a dummy variable to our benchmark specification (equation (7)). The initial values of this dummy are placed systematically along the range of IMEQ values from 0.055 to 0.185 , in increments of 0.005 . The idea is to test for changes in the slope of our variable of interest on the growth regression. The

11That the slope in the third interval is still positive is intuitively consistent with the fact that, as of 1995, relatively few countries had reached the dying-out stage for the technological groups chosen (SITC, Section 7). Supposedly, as more countries reach this stage, the slope in this interval will become flatter. However, the change in the simple correlation in the third interval, which reduces drastically with respect to the second interval but does not reach zero, is consistent with the metaphor of an infectious epidemic that remains chronic because of a positive rate of growth in the population.

${ }^{12}$ Two-stage least squares with lagged values as instruments, level-by-level, and within-group methods were applied as well. Although the results obtained are similar, these methods fail to pass either the Sargan test or some of the second- or third-order serial correlation tests.

${ }^{13}$ The use of alternative definitions does not affect results.

${ }^{14}$ Additional robustness checks were performed on our variable of interest by changing the benchmark specification. We repeated all the estimations excluding $O I N V$. Results do not change. Both IMEQ variables used (narrow and broad definition) are quite robust to changes in specification.

${ }^{15}$ We also tested equation (1) directly. We find that: $Y_{R}=0.38$ (s.e. 0.01 ), $\alpha=10.01$ (s.e. 1.43 ), and $\gamma$ $=14.56$ (s.e. 2.19) where $Y_{R}, \alpha$, and $\gamma$ yield the expected signs and are all statistically significant. We applied the following accumulation rule: $K(t)=I(t)+(1-d)^{*} K(t-1)$, where $K$ is the stock of capital, and $I$ is investment. We calculated the stock of technology $T$ by assuming a depreciation rate $d=6.7$ percent (Cooley, 1995) and used data in PPP 1990 U.S. dollars. These findings provide support to our hypothesis but may still be criticized since: (i) the calculation of technology stock and depreciation rates are arbitrary; (ii) there is no estimation of the varying size of new technologies on growth; and (iii) the methodology does not allow for the test of structural breaks other than logistic ones. 
Table 2. Imports of Machinery and Equipment and Economic Growth, Fixed-Effects Full-Sample Regressions 1, 2, 3,4

\begin{tabular}{|c|c|c|c|c|c|c|}
\hline & OLS & OLS* & GMM-IV & GMM-IV* & $\begin{array}{c}\text { GMM-IV } \\
\text { System }\end{array}$ & $\begin{array}{l}\text { GMM-IV } \\
\text { System * }\end{array}$ \\
\hline Constant & $\begin{array}{c}0.022 \\
(2.832)\end{array}$ & $\begin{array}{c}0.034 \\
(3.425)\end{array}$ & $\begin{array}{c}0.018 \\
(2.397)\end{array}$ & $\begin{array}{c}0.032 \\
(4.334)\end{array}$ & $\begin{array}{c}0.021 \\
(4.831)\end{array}$ & $\begin{array}{c}0.023 \\
(5.396)\end{array}$ \\
\hline$L G A P$ & $\begin{array}{c}-0.003 \\
(-1.029)\end{array}$ & $\begin{array}{c}-0.004 \\
(-1.148)\end{array}$ & $\begin{array}{c}-0.004 \\
(-1.308)\end{array}$ & $\begin{array}{c}-0.007 \\
(-2.284)\end{array}$ & $\begin{array}{c}-0.005 \\
(-3.099)\end{array}$ & $\begin{array}{c}-0.005 \\
(-3.016)\end{array}$ \\
\hline$S C H L$ & $\begin{array}{c}0.001 \\
(1.086)\end{array}$ & $\begin{array}{c}0.001 \\
(1.205)\end{array}$ & $\begin{array}{c}0.001 \\
(1.204)\end{array}$ & $\begin{array}{c}0.002 \\
(2.368)\end{array}$ & $\begin{array}{c}0.001 \\
(2.057)\end{array}$ & $\begin{array}{c}0.002 \\
(4.116)\end{array}$ \\
\hline$L A B G$ & $\begin{array}{c}-0.015 \\
(-0.489)\end{array}$ & $\begin{array}{c}-0.038 \\
(-1.173)\end{array}$ & $\begin{array}{c}0.023 \\
(0.912)\end{array}$ & $\begin{array}{c}-0.034 \\
(-1.448)\end{array}$ & $\begin{array}{c}0.016 \\
(1.232)\end{array}$ & $\begin{array}{c}-0.008 \\
(-0.610)\end{array}$ \\
\hline$I M E Q$ & $\begin{array}{c}0.115 \\
(5.013)\end{array}$ & $\begin{array}{c}0.162 \\
(5.467)\end{array}$ & $\begin{array}{c}0.135 \\
(6.874)\end{array}$ & $\begin{array}{c}0.154 \\
(8.158)\end{array}$ & $\begin{array}{c}0.145 \\
(13.975)\end{array}$ & $\begin{array}{c}0.159 \\
(16.637)\end{array}$ \\
\hline OINV & $\begin{array}{c}0.051 \\
(2.703)\end{array}$ & $\begin{array}{c}0.054 \\
(3.058)\end{array}$ & $\begin{array}{c}0.051 \\
(2.379)\end{array}$ & $\begin{array}{c}0.046 \\
(2.130)\end{array}$ & $\begin{array}{c}0.065 \\
(9.813)\end{array}$ & $\begin{array}{c}0.061 \\
(11.124)\end{array}$ \\
\hline Sargan Test & & & 0.025 & 0.068 & 0.101 & 0.151 \\
\hline $\begin{array}{l}\text { Correlation Tests } \\
\text { First Order } \\
\text { Second Order } \\
\text { Third Order }\end{array}$ & & & $\begin{array}{l}0.076 \\
0.576 \\
0.499\end{array}$ & $\begin{array}{l}0.028 \\
0.427 \\
0.535\end{array}$ & $\begin{array}{l}0.000 \\
0.981 \\
0.690\end{array}$ & $\begin{array}{l}0.001 \\
0.838 \\
0.897\end{array}$ \\
\hline $\begin{array}{l}\text { Countries } \\
\text { Observations }\end{array}$ & $\begin{array}{c}79 \\
362\end{array}$ & $\begin{array}{c}74 \\
311\end{array}$ & $\begin{array}{c}77 \\
357\end{array}$ & $\begin{array}{c}73 \\
333\end{array}$ & $\begin{array}{c}76 \\
276\end{array}$ & $\begin{array}{c}73 \\
260\end{array}$ \\
\hline
\end{tabular}

${ }^{1}$ Imports of machinery and equipment (IMEQ) comprises SITC Section 7. Narrow definition of IMEQ (columns with *) excludes transport equipment (Section 73); see pp. 7-8. All regressions include two-way fixed effects.

${ }^{2} t$-statistics in parenthesis.

${ }^{3}$ GMM-IV: Generalized method of moments estimator with instrumental variables.

${ }^{4}$ GMM-IV System: System estimator obtained by applying GMM-IV to the system of first differences; see Appendix II.

results are quite remarkable and give empirical support to our epidemics hypothesis. When a dummy variable is placed at the lower end of the IMEQ range of values such as $0.055,0.60$, or 0.65 , the resulting slope is not statistically different from zero. ${ }^{16}$ When the dummy variable is placed at 0.07 in the IMEQ range of values, the slope becomes positive and statistically significant under the GMM system estimator method. This may be indicating that the first threshold in our hypothesized epidemic pattern has been reached. As expected, in this second, or high-rate-of-contagion stage, the slope tends to increase along the range of IMEQ values, from about 0.089 to 0.159 , where it appears to peak. ${ }^{17}$ Thus, the value of 0.15 may be indicating the end of the second interval.

\footnotetext{
${ }^{16}$ While, as expected, the slope on the rest of the sample is relatively high, about 0.16 .

${ }^{17}$ Although the increases are not perfectly smooth and a slight decrease is observed before the slope increases again, the general tendency upward is clear.
} 


\section{Alberto Chong and Luisa Zanforlin}

\section{Table 3. Interval Location Approach 1,2}

Ordinary Least Squares with Fixed Effects

(79 countries, 362 observations)

Assigned Threshold on Range of IMEQ Values

\begin{tabular}{|c|c|c|c|c|c|c|}
\hline & 0.055 & 0.060 & 0.065 & 0.070 & 0.075 & 0.080 \\
\hline Dummy IMEQ & $\begin{array}{r}0.016 \\
(0.17)\end{array}$ & $\begin{array}{l}0.023 \\
(0.27)\end{array}$ & $\begin{array}{r}0.041 \\
(0.50)\end{array}$ & $\begin{array}{r}0.021 \\
(0.26)\end{array}$ & $\begin{array}{l}0.055 \\
(0.80)\end{array}$ & $\begin{array}{r}0.054 \\
(0.93)\end{array}$ \\
\hline $\begin{array}{l}\text { Threshold * (Dummy } \\
\text { IMEQ-Threshold) }\end{array}$ & $\begin{array}{r}0.116 \\
(1.12)\end{array}$ & $\begin{array}{l}0.113 \\
(1.14)\end{array}$ & $\begin{array}{c}0.095 \\
(0.98)\end{array}$ & $\begin{array}{l}0.126 \\
(1.32)\end{array}$ & $\begin{array}{c}0.085 \\
(0.99)\end{array}$ & $\begin{array}{r}0.091 \\
(1.24)\end{array}$ \\
\hline $\begin{array}{l}\text { Slope } 1 \\
\text { Slope } 2\end{array}$ & $\begin{array}{l}0.016 \\
0.133\end{array}$ & $\begin{array}{l}0.023 \\
0.136\end{array}$ & $\begin{array}{l}0.041 \\
0.136\end{array}$ & $\begin{array}{l}0.021 \\
0.147\end{array}$ & $\begin{array}{l}0.055 \\
0.140\end{array}$ & $\begin{array}{l}0.054 \\
0.145\end{array}$ \\
\hline
\end{tabular}

GMM-IV System Estimator with Fixed Effects

(77 countries, 280 observations)

Assigned Threshold on Range of IMEQ Values

\begin{tabular}{|c|c|c|c|c|c|c|}
\hline & 0.055 & 0.060 & 0.065 & 0.070 & 0.075 & 0.080 \\
\hline Dummy IMEQ & $\begin{array}{r}0.000 \\
(-0.01)\end{array}$ & $\begin{array}{l}0.041 \\
(0.86)\end{array}$ & $\begin{array}{c}0.071 \\
(1.77)\end{array}$ & $\begin{array}{r}0.089 \\
(2.64)\end{array}$ & $\begin{array}{l}0.113 \\
(3.73)\end{array}$ & $\begin{array}{r}0.134 \\
(4.85)\end{array}$ \\
\hline $\begin{array}{l}\text { Threshold * (Dummy } \\
\text { IMEQ-Threshold) }\end{array}$ & $\begin{array}{l}0.163 \\
(2.59)\end{array}$ & $\begin{array}{l}0.121 \\
(2.22)\end{array}$ & $\begin{array}{r}0.089 \\
(1.91)\end{array}$ & $\begin{array}{l}0.067 \\
(1.69)\end{array}$ & $\begin{array}{c}0.039 \\
(1.07)\end{array}$ & $\begin{array}{r}0.013 \\
(0.37)\end{array}$ \\
\hline $\begin{array}{l}\text { Sargan Test } \\
\text { Correlation Tests }\end{array}$ & 0.171 & 0.184 & 0.186 & 0.187 & 0.190 & 0.198 \\
\hline $\begin{array}{l}\text { First Order } \\
\text { Second Order } \\
\text { Third Order }\end{array}$ & $\begin{array}{l}0.000 \\
0.962 \\
0.698\end{array}$ & $\begin{array}{l}0.000 \\
0.968 \\
0.698\end{array}$ & $\begin{array}{l}0.000 \\
0.975 \\
0.694\end{array}$ & $\begin{array}{l}0.000 \\
0.981 \\
0.684\end{array}$ & $\begin{array}{l}0.000 \\
0.983 \\
0.683\end{array}$ & $\begin{array}{l}0.000 \\
0.986 \\
0.687\end{array}$ \\
\hline $\begin{array}{l}\text { Slope } 1 \\
\text { Slope } 2\end{array}$ & $\begin{array}{l}0.000 \\
0.162\end{array}$ & $\begin{array}{l}0.041 \\
0.162\end{array}$ & $\begin{array}{l}0.071 \\
0.159\end{array}$ & $\begin{array}{l}0.089 \\
0.157\end{array}$ & $\begin{array}{l}0.113 \\
0.152\end{array}$ & $\begin{array}{l}0.134 \\
0.146\end{array}$ \\
\hline
\end{tabular}

${ }^{1}$ Results obtained are based on growth specification in equation (7); $t$-statistics are in parentheses.

${ }^{2}$ Slope 1 and 2 refer to the coefficients of IMEQ in the different intervals.

Consistent with a third or dying-out stage, dummy variables, when placed progressively higher in the IMEQ range, tend to yield a slope along a decreasing path. The slope goes from 0.157 to 0.137 in this interval. However, as can be seen in the symmetric slope (slope 2 in the table), this third stage does not yield nonsignificant slopes: they are still positive and significant. ${ }^{18}$ The OLS method

${ }^{18}$ Additional regressions (not reported) with dummy variables placed to the right of 0.185 are consistent with this finding. This is similar to the findings reported above that were obtained with simple correlations. 
Table 3. Interval Location Approach 1,2 (continued)

Ordinary Least Squares with Fixed Effects

(79 countries, 362 observations)

Assigned Threshold on Range of IMEQ Values

$\begin{array}{lccccccc} & 0.085 & 0.090 & 0.095 & 0.100 & 0.105 & 0.110 & 0.115 \\ \text { Dummy IMEQ } & 0.067 & 0.078 & 0.085 & 0.092 & 0.104 & 0.107 & 0.116 \\ & (1.24) & (1.52) & (1.74) & (1.95) & (2.40) & (2.64) & (3.12) \\ \text { Threshold * (Dummy } & & & & & & & \\ \text { IMEQ-Threshold) } & 0.075 & 0.060 & 0.051 & 0.041 & 0.021 & 0.016 & -0.001 \\ & (1.07) & (0.88) & (0.75) & (0.61) & (0.34) & (0.27) & (-0.03) \\ \text { Slope 1 } & & & & & & & \\ \text { Slope 2 } & 0.067 & 0.078 & 0.085 & 0.092 & 0.104 & 0.107 & 0.116 \\ & 0.142 & 0.138 & 0.136 & 0.133 & 0.125 & 0.123 & 0.114\end{array}$

GMM-IV System Estimator with Fixed Effects

(77 countries, 280 observations)

\begin{tabular}{|c|c|c|c|c|c|c|c|}
\hline & \multicolumn{7}{|c|}{ Assigned Threshold on Range of IMEQ Values } \\
\hline & 0.085 & 0.090 & 0.095 & 0.100 & 0.105 & 0.110 & 0.115 \\
\hline \multirow[t]{2}{*}{ Dummy IMEQ } & 0.144 & 0.153 & 0.158 & 0.157 & 0.152 & 0.146 & 0.144 \\
\hline & $(5.65)$ & $(6.63)$ & $(7.68)$ & $(8.57)$ & $(9.40)$ & $(10.26)$ & $(11.21)$ \\
\hline \multicolumn{8}{|l|}{ Threshold * (Dummy } \\
\hline IMEQ-Threshold) & $\begin{array}{c}-0.002 \\
(-0.06)\end{array}$ & $\begin{array}{c}-0.016 \\
(-0.55)\end{array}$ & $\begin{array}{l}-0.027 \\
(-1.01)\end{array}$ & $\begin{array}{l}-0.026 \\
(-1.12)\end{array}$ & $\begin{array}{l}-0.021 \\
(-1.01)\end{array}$ & $\begin{array}{c}-0.015 \\
(-0.83)\end{array}$ & $\begin{array}{l}-0.016 \\
(-0.92)\end{array}$ \\
\hline Sargan Test & 0.207 & 0.217 & 0.227 & 0.235 & 0.233 & 0.214 & 0.191 \\
\hline \multicolumn{8}{|l|}{ Correlation Tests } \\
\hline First Order & 0.000 & 0.000 & 0.000 & 0.000 & 0.000 & 0.000 & 0.000 \\
\hline Second Order & 0.987 & 0.989 & 0.992 & 0.993 & 0.994 & 0.990 & 0.986 \\
\hline Third Order & 0.689 & 0.691 & 0.692 & 0.690 & 0.686 & 0.684 & 0.688 \\
\hline Slope 1 & 0.144 & 0.153 & 0.158 & 0.157 & 0.152 & 0.146 & 0.144 \\
\hline Slope 2 & 0.142 & 0.137 & 0.132 & 0.131 & 0.132 & 0.131 & 0.128 \\
\hline
\end{tabular}

${ }^{1}$ Results obtained are based on growth specification in equation (7); $t$-statistics are in parentheses. ${ }^{2}$ Slope 1 and 2 refer to the coefficients of IMEQ in the different intervals.

yields similar results. The path of the slope follows the same pattern as in the GMM system estimator method although the statistical significance of the methods tends to differ. This may be due to bias in the estimators because of endogeneity. Both the GMM system and OLS slope patterns are also graphed in Figure 5 and Figure 6. Notice the concavity in the corresponding or "lower end" slopes and the relative stability in the symmetric or "higher end" slopes. Moreover, since most of the lower end slopes are statistically nonsignificant, the actual pattern resembles the hypothesized shape. Thus, by using this simple 
Table 3. Interval Location Approach 1,2 (continued)

Ordinary Least Squares with Fixed Effects

(79 countries, 362 observations)

\section{Assigned Threshold on Range of IMEQ Values}

$\begin{array}{lrrrrrr} & 0.120 & 0.125 & 0.130 & 0.135 & 0.140 & 0.145 \\ \text { Dummy IMEQ } & 0.118 & 0.120 & 0.123 & 0.123 & 0.125 & 0.123 \\ & (3.22) & (3.32) & (3.46) & (3.54) & (3.65) & (3.67) \\ \text { Threshold * (Dummy } & & & & & & \\ \text { IMEQ-Threshold) } & -0.007 & -0.011 & -0.020 & -0.022 & -0.028 & -0.023 \\ & (-0.11) & (-0.19) & (-0.32) & (-0.35) & (-0.43) & (-0.36) \\ \text { Slope 1 } & & & & & & \\ \text { Slope 2 } & 0.118 & 0.120 & 0.123 & 0.123 & 0.125 & 0.123 \\ & 0.111 & 0.108 & 0.103 & 0.101 & 0.097 & 0.100\end{array}$

GMM-IV System Estimator with Fixed Effects (77 countries, 280 observations)

Assigned Threshold on Range of IMEQ Values

$\begin{array}{lrrrrrr} & 0.120 & 0.125 & 0.130 & 0.135 & 0.140 & 0.145 \\ \text { Dummy IMEQ } & \begin{array}{r}0.144 \\ (12.01)\end{array} & \begin{array}{r}0.147 \\ (12.85)\end{array} & \begin{array}{r}0.151 \\ (13.86)\end{array} & \begin{array}{r}0.154 \\ (14.83)\end{array} & \begin{array}{r}0.157 \\ (15.55)\end{array} & \begin{array}{r}0.156 \\ (15.43)\end{array} \\ \begin{array}{l}\text { Threshold * (Dummy } \\ \text { IMEQ-Threshold) }\end{array} & \begin{array}{r}-0.018 \\ (-1.15)\end{array} & \begin{array}{r}-0.025 \\ (-1.69)\end{array} & \begin{array}{r}-0.033 \\ (-2.40)\end{array} & \begin{array}{r}-0.038 \\ (-2.77)\end{array} & \begin{array}{r}-0.046 \\ (-3.30)\end{array} & \begin{array}{r}-0.048 \\ (-3.48)\end{array} \\ & & & & & & \\ & 0.179 & 0.170 & 0.163 & 0.236 & 0.228 & 0.238 \\ \text { Sargan Test } & 0.000 & 0.000 & 0.000 & 0.000 & 0.000 & 0.000 \\ \text { Correlation Tests } & 0.985 & 0.985 & 0.986 & 0.999 & 0.997 & 0.996 \\ \quad \begin{array}{l}\text { First Order } \\ \text { Second Order }\end{array} & 0.694 & 0.697 & 0.707 & 0.704 & 0.710 & 0.714 \\ \quad \text { Third Order } & & & & & & \\ & 0.144 & 0.147 & 0.151 & 0.154 & 0.157 & 0.156 \\ \text { Slope 1 } & 0.126 & 0.122 & 0.117 & 0.116 & 0.111 & 0.108\end{array}$

${ }^{1}$ Results obtained are based on growth specification in equation (7); $t$-statistics are in parentheses. ${ }^{2}$ Slope 1 and 2 refer to the coefficients of IMEQ in the different intervals.

method, we are able to identify roughly the possible thresholds of the three stages in our linearized epidemic pattern. These possible intervals are [min IMEQ-0.07], [0.07-0.15], [0.15-max IMEQ].

We use these intervals and apply the unrestricted approach described in the empirical strategy section. Results are shown in Table 4. The idea is to apply equation (7) and run fixed-effects regressions for the subsamples according to these identified intervals, and test for differences in the slopes. Again, the 
Table 3. Interval Location Approach ${ }^{1,2}$ (concluded)

Ordinary Least Squares with Fixed Effects

(79 countries, 362 observations)

Assigned Threshold on Range of IMEQ Values

$\begin{array}{lrrrrrrrrr} & 0.150 & 0.155 & 0.160 & 0.165 & 0.170 & 0.175 & 0.180 & 0.185 \\ \text { Dummy IMEQ } & 0.122 & 0.122 & 0.122 & 0.113 & 0.113 & 0.115 & 0.115 & 0.115 \\ & (3.67) & (3.71) & (3.74) & (3.60) & (3.80) & (3.94) & (3.97) & (4.00) \\ \text { Threshold * (Dummy } & & & & & & & & \\ \text { IMEQ-Threshold) } & -0.020 & -0.021 & -0.022 & 0.005 & 0.007 & -0.002 & -0.001 & 0.001 \\ & (-0.30) & (-0.31) & (-0.32) & (0.09) & (0.12) & (-0.04) & (-0.01) & (0.02) \\ \text { Slope 1 } & & & & & & & & \\ \text { Slope 2 } & 0.122 & 0.122 & 0.122 & 0.113 & 0.113 & 0.115 & 0.115 & 0.115 \\ & 0.102 & 0.101 & 0.100 & 0.119 & 0.120 & 0.113 & 0.114 & 0.116\end{array}$

GMM-IV System Estimator with Fixed Effects

(77 countries, 280 observations)

\begin{tabular}{lrrrrrrrrr} 
& \multicolumn{8}{c}{ Assigned Threshold on Range of IMEQ Values } \\
& 0.150 & 0.155 & 0.160 & 0.165 & 0.170 & 0.175 & 0.180 & 0.185 \\
& & & & & & & & \\
& 0.159 & 0.157 & 0.155 & 0.153 & 0.148 & 0.143 & 0.140 & 0.137 \\
& $(13.16)$ & $(13.08)$ & $(12.88)$ & $(12.79)$ & $(12.23)$ & $(11.80)$ & $(11.62)$ & $(11.20)$ \\
& & & & & & & & \\
Dummy IMEQ & -0.052 & -0.051 & -0.049 & -0.046 & -0.035 & -0.025 & -0.019 & -0.011 \\
IMEQ-Threshold) & $(-3.22)$ & $(-3.13)$ & $(-3.08)$ & $(-2.96)$ & $(-2.00)$ & $(-1.41)$ & $(-1.07)$ & $(-0.50)$ \\
& & & & & & & & \\
& 0.240 & 0.243 & 0.247 & 0.256 & 0.261 & 0.261 & 0.262 & 0.266 \\
Sargan Test & & & & & & & & \\
Correlation Tests & 0.000 & 0.000 & 0.000 & 0.000 & 0.000 & 0.000 & 0.000 & 0.000 \\
$\quad \begin{array}{l}\text { First Order } \\
\quad \text { Second Order }\end{array}$ & 0.990 & 0.991 & 0.993 & 0.995 & 0.999 & 0.991 & 0.987 & 0.983 \\
$\quad$ Third Order & 0.713 & 0.711 & 0.709 & 0.706 & 0.700 & 0.697 & 0.695 & 0.692 \\
& & & & & & & & \\
Slope 1 & 0.159 & 0.157 & 0.155 & 0.153 & 0.148 & 0.143 & 0.140 & 0.137 \\
Slope 2 & 0.107 & 0.107 & 0.106 & 0.106 & 0.113 & 0.118 & 0.121 & 0.127
\end{tabular}

${ }^{1}$ Results obtained are based on growth specification in equation (7); $t$-statistics are in parentheses. ${ }^{2}$ Slope 1 and 2 refer to the coefficients of IMEQ in the different intervals.

resulting path is expected to be nonmonotonic, as argued in the theoretical section. Compared with the estimates of the full sample, estimates for the middle interval are clearly much higher, and this difference is statistically significant. For instance, using the GMM system estimator method, the coefficient of the middle interval is 0.20 (s.e. 0.07), but it is only 0.14 (s.e. 0.01 ) for the full sample. In order to provide further empirical confirmation of our findings, and as a simple way to check for local consistency, we allow for systematic 
Figure 5. Interval Location, OLS

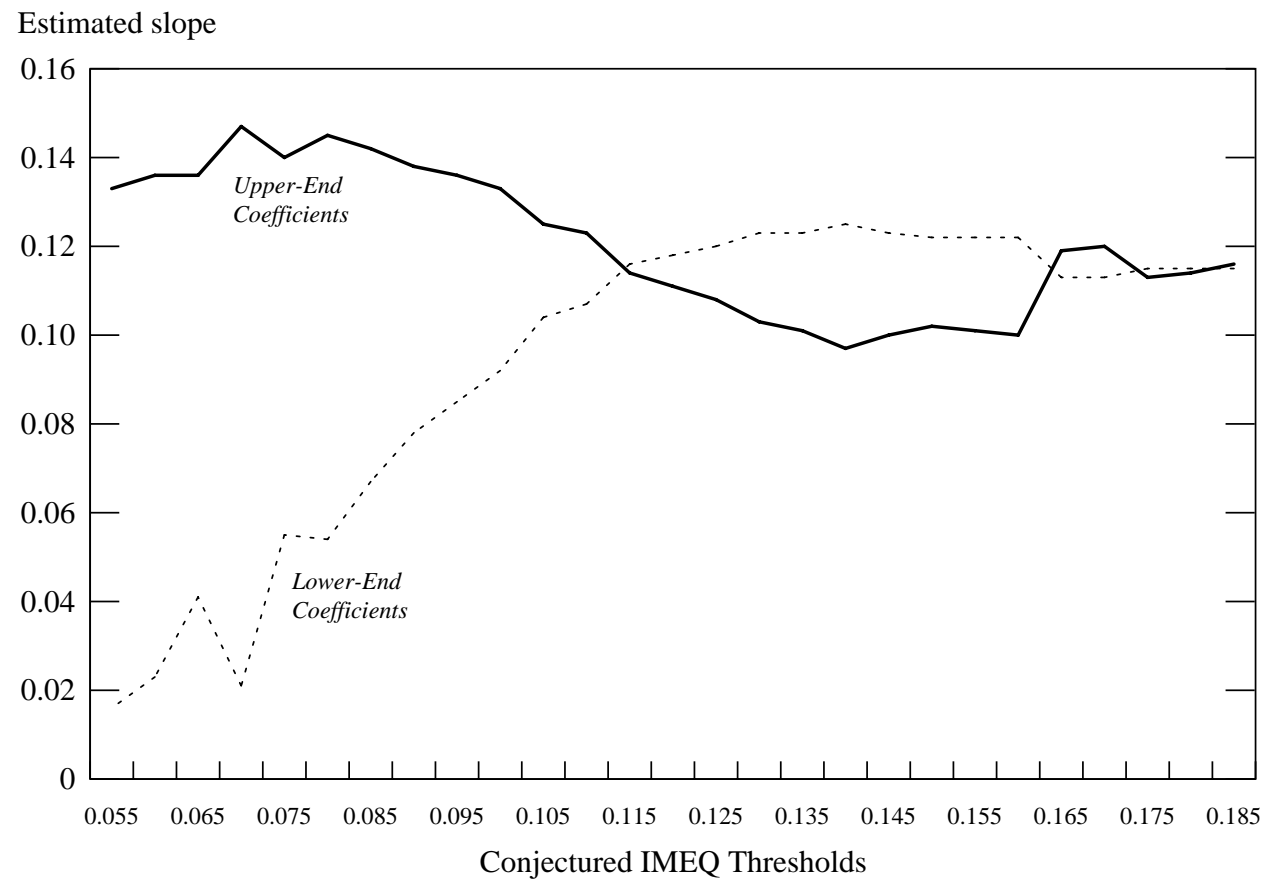

Figure 6. Interval Location, GMM System

Estimated slope

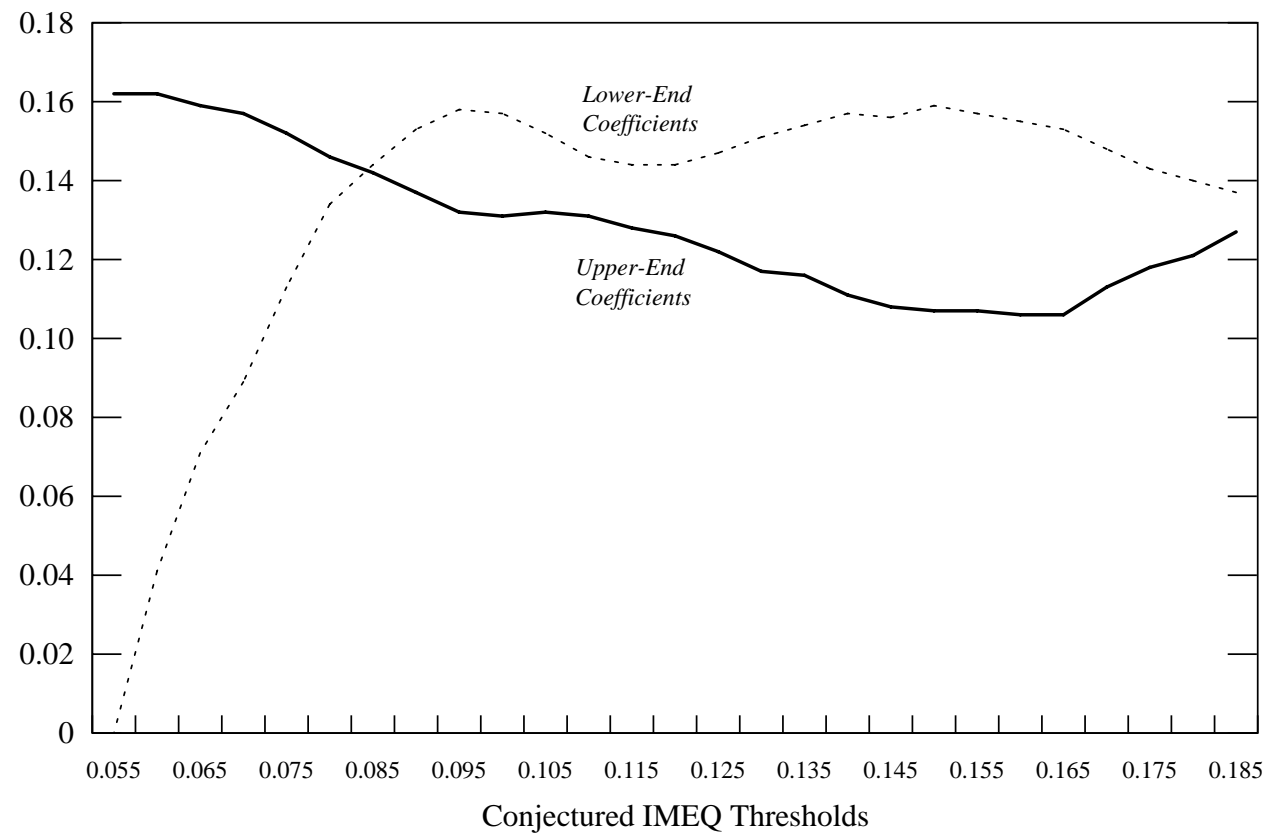




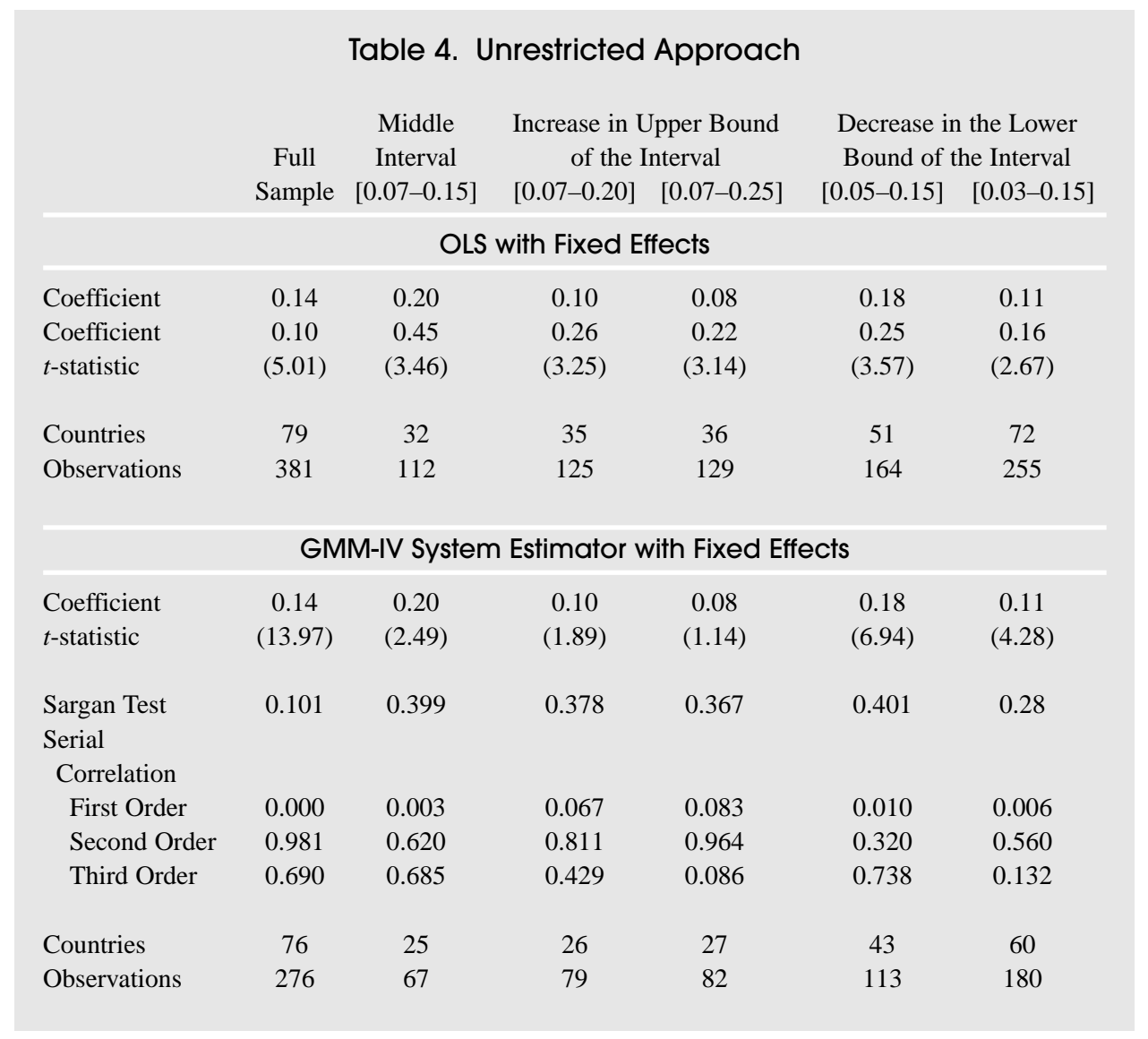

increases in the upper and lower thresholds around the identified middle interval. As expected, the coefficient on IMEQ declines the larger the local interval. For instance, the coefficient on IMEQ using the GMM system estimator case goes from 0.20 (s.e. 0.07) to 0.08 (s.e. 0.07) when we increase the upper bound of the middle interval to [0.07-0.25]. The difference in coefficients is significant. Likewise, when we allow for local increases in the lower threshold of the middle interval, we also obtain statistically significant decreases in the slope. Local increases and decreases in the extreme bounds yield statistically significant lower slopes. This outcome is consistent with an epidemics pattern and with the prediction of the model. Moreover, for the lower-end interval, [min IMEQ-0.07] the coefficient on IMEQ is not statistically significant regardless of the estimating technique. A similar result is obtained for the upper-end interval [0.15- max IMEQ]. ${ }^{19}$ Thus, the estimated

${ }^{19}$ The coefficients for both the lower- and upper-end intervals are statistically nonsignificant in most cases, regardless of the econometric technique, and in no case are they robust. In the case of the first interval, some estimates yield negative (but statistically nonsignificant) coefficients that become positive (and nonsignificant) if specifications are changed slightly. 
coefficient on IMEQ in the middle interval [0.07-0.15] is significantly greater than the coefficients obtained on the outer intervals. Again, this outcome is consistent with the existence of an epidemic pattern.

Finally, Table 5 shows the results of the spline regressions using equation (7). In this case, we add two dummy variables and use the full sample (79 countries and 362 observations with the OLS method and 77 countries and 280 observations in the GMM system estimator method) in order to measure the slopes of the three intervals, if any. We use the same intervals that we identified before. Thus, the high-rate-of-contagion stage is assumed to be located at [0.07-0.15]. The results are consistent with our previous findings and provide additional supporting evidence for the existence of nonlinearities in the link between technology and output. In fact, the results seem to confirm our hypothesis that such a link follows an epidemic pattern. The last column in Table 5 shows the results for the three intervals we identified before. The first slope, the one corresponding to the incubation stage, is indeed not significantly different from zero. The second slope, corresponding to the high-rate-of-contagion stage, is positive and statistically significant: 0.248 in the GMM system estimator method and 0.216 using OLS. Similar to those obtained under the unrestricted approach, these slopes are substantially higher than the corresponding purely linear ones $(0.15$ and 0.14 , respectively). Finally, the third slope, corresponding to the dying-out stage, although somewhat positive, decreases drastically with respect to the second stage (0.09 using the GMM system estimator method and 0.08 using OLS). As we did under the unrestricted approach, we perform some local consistency checks by tracing the path of the slope around the identified high-rate-of-contagion interval. To do this, we simply widen this interval systematically by increasing the upper and lower bounds by increments of 0.005 around the original interval. The slopes of the first and third stages remain close to zero, while the slope of the second stage tends to decline as documented on columns $1-4$ of Table $5 .{ }^{20}$ Again, this result is consistent with an epidemic pattern.

\section{Summary and Conclusions}

We have presented evidence that supports the hypothesis that the impact of new foreign technology on output follows a pattern analogous to that of typical infectious epidemics. A stylized fact seems to be that the impact of technology on output may follow three stages: "incubation," "high-rate-of-contagion," and "dying-out." We apply three complementary simple methods that assume a linearized "epidemics" link between technology and output and focus on the slope of such a relationship, which may be measured via growth regressions. If an epidemic pattern characterizes the relationship between technology and output, such a pattern should be reflected in the path of the slope on the technology flow

\footnotetext{
${ }^{20} \mathrm{An}$ exception occurs when the middle interval is [0.05-0.17] under the GMM system estimator method. The slope in the first stage is 0.12 , clearly positive; however, it is still lower than the one in the middle stage (0.17).
} 
Table 5. Restricted Approach 1,2,3,4

\section{OLS with Fixed Effects}

Threshold 1

Threshold 2

IMEQ

Threshold 1(IMEQ-threshold 1)

Threshold 2 (IMEQ-threshold 2)

Slope 1

Slope 2

Slope 3
Interval location

$[0.050-[0.055-\quad[0.060-\quad[0.065-\quad[0.070-$

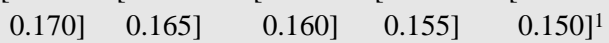

$\begin{array}{lllll}0.037 & 0.004 & 0.000 & 0.018 & -0.004\end{array}$

$\begin{array}{lllll}(0.35) & (0.04) & (0.00) & (0.20) & (-0.06)\end{array}$

$\begin{array}{lllll}0.102 & 0.146 & 0.176 & 0.163 & 0.221\end{array}$

$\begin{array}{lllll}(0.89) \quad(1.21) & (1.43) \quad(1.32)\end{array}$

$\begin{array}{lllll}-0.060 & -0.042 & -0.090 & -0.093 & -0.133\end{array}$

$\begin{array}{lllll}(-2.24) \quad(-0.62) & (-1.11) \quad(-1.13) \quad(-1.56)\end{array}$

$\begin{array}{llllr}0.0373 & 0.0040 & 0.0002 & 0.0180 & -0.0048 \\ 0.1397 & 0.1500 & 0.1766 & 0.1813 & 0.2164 \\ 0.0796 & 0.1073 & 0.0860 & 0.0879 & 0.0830\end{array}$

GMM-IV System Estimator with Fixed Effects

\begin{tabular}{|c|c|c|c|c|c|}
\hline \multirow{3}{*}{$\begin{array}{l}\text { Threshold } 1 \\
\text { Threshold } 2\end{array}$} & \multicolumn{5}{|c|}{ Interval Location } \\
\hline & {$[0.050-$} & {$[0.055-$} & {$[0.060-$} & {$[0.065-$} & {$[0.070-$} \\
\hline & $0.170]$ & $0.165]$ & $0.160]$ & $0.155]$ & $0.150]$ \\
\hline \multirow[t]{2}{*}{ IMEQ } & 0.121 & -0.049 & -0.025 & 0.018 & 0.049 \\
\hline & $(2.90)$ & $(-1.21)$ & $(-0.68)$ & $(0.51)$ & (1.61) \\
\hline \multirow[t]{2}{*}{ Threshold 1 (IMEQ-Threshold 1) } & 0.051 & 0.276 & 0.268 & 0.228 & 0.199 \\
\hline & (1.07) & $(5.34)$ & $(5.16)$ & $(4.31)$ & $(4.14)$ \\
\hline \multirow[t]{2}{*}{ Threshold 2 (IMEQ-Threshold 2) } & -0.120 & -0.139 & -0.156 & -0.155 & -0.157 \\
\hline & $(-15.07)$ & $(-6.80)$ & $(-6.47)$ & $(-6.07)$ & $(-6.20)$ \\
\hline Sargan Test & 0.503 & 0.438 & 0.418 & 0.410 & 0.418 \\
\hline \multicolumn{6}{|l|}{ Correlation Tests } \\
\hline First Order & 0.000 & 0.000 & 0.000 & 0.000 & 0.000 \\
\hline Second Order & 0.694 & 0.973 & 0.972 & 0.962 & 0.951 \\
\hline Third Order & 0.659 & 0.717 & 0.734 & 0.730 & 0.717 \\
\hline Slope 1 & 0.1211 & -0.0485 & -0.0253 & 0.0181 & 0.0487 \\
\hline Slope 2 & 0.1719 & 0.2272 & 0.2424 & 0.2457 & 0.2482 \\
\hline Slope 3 & 0.0520 & 0.0879 & 0.0869 & 0.0911 & 0.0908 \\
\hline \multicolumn{6}{|c|}{$\begin{array}{l}{ }^{1} \text { Identified as high-rate-of-contagion interval. All } t \text {-statistics are in parentheses. Est } \\
\text { ained are based on equation ( } 7 \text { ) in text. }\end{array}$} \\
\hline
\end{tabular}

proxy, imports of machinery and equipment. In the general case, such a path, it is theoretically shown, should also be nonmonotonic. In particular, in its linearized form, it should yield three slopes that correspond to the three stages of the linearized epidemic pattern. 
We proceed by applying a systematic method that identifies the intervals that represent the three stages described above. We claim the extreme values of these intervals to be around some specific values, and from there we use both an unrestricted and a restricted approach to test for differences in the slopes of our variable of interest. While the former approach cuts the full sample into sub-samples and allows all the regressors to adjust, the latter applies a spline approach. Both approaches seem to confirm our hypothesis. We perform local consistency checks by tracing the path of the slopes around the thresholds, changing the benchmark specification, applying different econometric techniques, and checking for outliers. ${ }^{21}$ The basic hypothesis appears to be further confirmed by all these tests. However, it should be said that even though our method gives indication on the shape and location of the hypothesized nonlinearities, our approach should be seen more as a first approximation in order to use a more sophisticated method. We believe that this contribution is not trivial, as it may well occur that testing for nonlinearities in panel data with more "direct" methods may yield statistically nonsignificant or nonrobust results although nonlinearities may be present. Perhaps there are three advantages in the approach used here: simplicity, flexibility, and easy application of sensitivity analysis.

Even though we use different data, the coefficients we obtain for the high-rateof-contagion stage are similar to those reported by De Long and Summers (1993) and Temple (1998), but are larger than those obtained by Auerbach, Hassett, and Oliner (1994) and Lee (1995). However, the coefficients of our full linear sample are closer to those of Auerbach, Hassett, and Oliner; and Lee. This paper suggests that both sets of results in literature are compatible once account has been taken of nonlinearity in the effect of imported equipment. Nonlinearities seem to play an important role in the technology-output relationship and, thus, in the growth process.

${ }^{21}$ We followed Temple (1998) to check for outliers. Results do not change. 


\section{APPENDIX I}

\section{Countries in Sample}

\begin{tabular}{|c|c|c|}
\hline Africa & Middle East and South Asia & OECD \\
\hline 1 Algeria & 28 India & 57 Australia \\
\hline 2 Cameroon & 29 Israel & 58 Austria \\
\hline 3 Central African Republic & 30 Jordan & 59 Belgium \\
\hline 4 Congo & 31 Myanmar & 60 Cyprus \\
\hline 5 Egypt & 32 Nepal & 61 Canada \\
\hline 6 Ghana & 33 Pakistan & 62 Denmark \\
\hline 7 Kenya & 34 Syria & 63 Finland \\
\hline 8 Malawi & 35 Sri Lanka & 64 Germany \\
\hline 9 Mali & 36 Thailand & 65 Greece \\
\hline 10 Mauritius & & 66 Iceland \\
\hline 11 Rwanda & Latin America & 67 Ireland \\
\hline 12 Senegal & 37 Argentina & 68 Italy \\
\hline 13 Sierra Leone & 38 Barbados & 69 Japan \\
\hline 14 South Africa & 39 Bolivia & 70 Netherlands \\
\hline 15 Togo & 40 Brazil & 71 New Zealand \\
\hline 16 Tunisia & 41 Chile & 72 Norway \\
\hline 17 Uganda & 42 Colombia & 73 Portugal \\
\hline 18 Zaïre & 43 Costa Rica & 74 Spain \\
\hline \multirow[t]{2}{*}{19 Zimbabwe } & 44 Dominican Republic & 75 Sweden \\
\hline & 45 Ecuador & 76 Switzerland \\
\hline Asia and Pacific & 46 El Salvador & 77 Turkey \\
\hline 20 Fiji & 47 Guatemala & 78 United States \\
\hline 21 Hong Kong, SAR & 48 Haiti & 79 United Kingdom \\
\hline 22 Indonesia & 49 Honduras & \\
\hline 23 Korea & 50 Jamaica & \\
\hline 24 Malaysia & 51 Mexico & \\
\hline 25 Papua New Guinea & 52 Paraguay & \\
\hline 26 Philippines & 53 Peru & \\
\hline \multirow[t]{3}{*}{27 Singapore } & 54 Trinidad and Tobago & \\
\hline & 55 Uruguay & \\
\hline & 56 Venezuela & \\
\hline
\end{tabular}




\section{APPENDIX II}

\section{Econometric Methodology22}

Recently developed dynamic panel data techniques allow us to address potential endogeneity problems as well as possible unobserved time and country-specific effects that may produce biased and inconsistent estimates. ${ }^{23}$ This methodology formulates a set of moment conditions that can be estimated using GMM techniques in order to generate consistent and efficient estimates. We assume that the error process $\left\{\varepsilon_{i, t}\right\}$ is serially uncorrelated and uses a first-difference specification of $N$ individual time series and $T$ periods, so that:

$$
y_{i, t}-y_{i, t-1}=\alpha\left(y_{i, t-1}-y_{i, t-2}\right)+\beta\left(x_{i, t}-x_{i, t-1}\right)+\mu_{i}+\left(\varepsilon_{i, t}-\varepsilon_{i, t-1}\right)
$$

where $y$ is the dependent variable and $x$ a set of explanatory variables. By construction, in equation (8) the error term and the lagged dependent variable are correlated. In order to achieve the desired parameters, we follow previous research and assume the presence of unobserved effects and weakly exogenous regressors. Our first assumption states that $\left\{\varepsilon_{i, t}\right\}$ is serially uncorrelated, that is $E\left(\varepsilon_{i, t} \varepsilon_{i, s}\right)=0$ for $t \neq s$ for $T \geq 3$. This assumption implies the following linear moment conditions:

$$
E\left[\left(\varepsilon_{i, t}-\varepsilon_{i, t-1}\right) y_{i, t-j}\right]=0(j=2, \ldots, t-1 ; t=3, \ldots, T) .
$$

The assumption of weakly exogenous regressors states that $E\left[x_{i, t} \varepsilon_{i, s}\right]=0$ for $s>t$. Hence, for $T \geq 3$, this assumption implies the following additional linear moment conditions:

$$
E\left[\left(\varepsilon_{i, t}-\varepsilon_{i, t-1}\right) x_{i, t-j}\right]=0(j=2, \ldots, t-1 ; t=3, \ldots, T)
$$

Our moment conditions, equations (9) and (10), can be written in the following vector form: $E\left[Z_{i}^{\prime} \zeta_{i}\right]=0$, where the instrument matrix, $Z_{i}$, is a matrix of the form $Z_{i}=\operatorname{diag}\left(y_{i, 1} \ldots y_{i, s}, x_{i, 1}\right.$ $\left.\ldots x_{i, s}\right), s=1,2, \ldots, T-2$, and the errors of the first-differenced equation is $\zeta_{i}=$ $\left[\left(\varepsilon_{i, 3}-\varepsilon_{i, 2}\right) \ldots\left(\varepsilon_{i, T}-\varepsilon_{i, T-1}\right)\right]^{\prime} .{ }^{24}$ The estimator of the $k x 1$ coefficient vector $\theta=\left(\alpha \beta^{\prime}\right)^{\prime}$ is given by:

${ }^{22}$ This section draws from Calderón, Chong, and Zanforlin (2001), Calderón, Chong, and Loayza (2002), and Chong and Zanforlin (2001).

${ }^{23}$ For instance, Alonso-Borrego and Arellano (1999), Arellano and Bond (1991), Arellano and Bover (1995), Blundell and Bond (1997), Holtz-Eakin, Newey, and Rosen (1988), Kiviet (1995), and Ziliak (1997). As is known, these two issues, and in particular the first one, have dominated the discussion on trade and growth in recent years. Frankel and Romer (1996), Frankel, Romer, and Cyrus (1996), and Harrison (1996) provide literature reviews. Chong and Zanforlin (2001) apply dynamic panel methods to the link between exports and growth.

${ }^{24}$ The number of columns of $Z_{i}$, for example, a matrix of rank column $M$, is equal to the number of available instruments. 


\section{TECHNOLOGY AND EPIDEMICS}

$\hat{\theta}=\left(\overline{\mathbf{X}}^{\prime} Z \Omega^{-1} Z^{\prime} \overline{\mathbf{X}}\right)^{-\mathbf{1}} \overline{\mathbf{X}}^{\prime} \mathbf{Z} \Omega^{-\mathbf{1}} \mathbf{Z}^{\prime} \bar{y}$, where $\overline{\mathbf{X}}$ is a stacked $(T-2) N \times k$ matrix of observations $\bar{x}_{i, t}^{\prime}$ on $\bar{y}_{i, t-1}^{\prime}$ and $\bar{y}$ is a stacked $(T-2) N$ x 1 vector of $\bar{y}_{i, t}^{\prime} ; \boldsymbol{Z}=\left(Z_{i}^{\prime} \ldots \boldsymbol{Z}_{N}^{\prime}\right)^{\prime}$ is a $(T-2) N$ x $M$ matrix; and $\Omega$ is any $M \times M$, symmetric, positive definite matrix. A bar denotes that the variables are expressed in first differences. For an arbitrary $\Omega$, a consistent estimate of the asymptotic variance-covariance matrix of $\hat{\theta}$ is given by:

$$
\operatorname{Asy} \cdot \operatorname{Var}(\hat{\boldsymbol{\theta}})=N\left(\overline{\mathbf{X}}^{\prime} \mathbf{Z} \boldsymbol{\Omega}^{-1} \mathbf{Z}^{\prime} \overline{\mathbf{X}}\right)^{-1} \overline{\mathbf{X}}^{\prime} \mathbf{Z} \boldsymbol{\Omega}^{-1}\left[\sum_{i=1}^{n} \mathbf{Z}_{i}^{\prime} \hat{v}_{i} \hat{v}_{i}^{\prime} \mathbf{Z}_{i}\right] \boldsymbol{\Omega}^{-1} \mathbf{Z}^{\prime} \overline{\mathbf{X}}\left(\overline{\mathbf{X}}^{\prime} \mathbf{Z} \boldsymbol{\Omega}^{-1} \mathbf{Z}^{\prime} \overline{\mathbf{X}}\right)^{-1},
$$

when $\Omega$ is chosen such that $\boldsymbol{V}=E\left[Z_{i}^{\prime} v_{i} v_{i}^{\prime} Z_{i}\right]$ we obtain the most efficient GMM estimator for $\theta$. This covariance matrix may be consistently estimated using the residuals obtained from a preliminary, consistent estimation of $\theta$. We first assumed that $\left\{\varepsilon_{i, t}\right\}$ is independent and homoskedastic both across units and over time. We relax such assumptions across units and use the residuals obtained in the first step to construct a consistent estimate of the variancecovariance matrix of the moment conditions. This matrix, denoted by $\Omega_{2}$, becomes the optimal choice of $\Omega$ and is used to re-estimate the coefficients of interest. Here, $\Omega_{2}=(1 / N) \Sigma_{i=1} Z_{i}^{\prime} \hat{\eta}_{i}^{1} \hat{\eta}_{i}^{1}$ $Z_{i}$, where $\hat{\eta}_{i}^{1}$ are the residuals estimated in the first step. Because the persistence of lagged dependent and explanatory variables over time might generate inconsistent estimates that might have adverse consequences on both the asymptotic and small-sample performance of the difference estimators, we use an estimator that complements the moment conditions applied above to the regression in differences with appropriate moment conditions applied to the regression in levels (Arellano and Bover, 1995). We obtain a system estimator that combines the regression in differences with the regression in levels. Here, the instruments for the regression in differences are the lagged levels of the corresponding variables, and the moment conditions in equations (9) and (10) apply to this first part of the system.

The instruments for the regression in levels are the lagged differences of the corresponding variables; these are the appropriate instruments under the two assumptions that (i) the error term $\varepsilon$ is not serially correlated, and (ii) although there may be some correlation between the levels of the explanatory variables and the country-specific effects, there is no correlation between the differences of these variables and the country-specific effects. This yields the stationary properties: $E\left[y_{i, t+p} \mu_{i}\right]=E\left[y_{i, t+q} \mu_{i}\right] ; \forall p, q$; and, $E\left[X_{i, t+p} \mu_{i}\right]=E\left[X_{i, t+q} \mu_{i}\right] ; \forall p, q$. The additional moment conditions for the second part of the system (the regression in levels) are given by $E\left[\left(y_{i, t-s}-y_{i, t-s-1}\right)\left(\mu_{i}+\varepsilon_{i, t}\right)\right]=0$; for $s=2, E\left[\left(X_{i, t-s}-X_{i, t-s-1}\right)\left(\mu_{i}+\varepsilon_{i, t}\right)\right]=0$, for $s=1$. Finally, we use Sargan tests to verify the overall validity of the instruments and serial correlation tests to examine the hypothesis that the error term in the difference regression $\varepsilon_{i, t}-\varepsilon_{i, t-1}$, is not second-order serially correlated.

\section{REFERENCES}

Alonso-Borrego, Cesar, and Manuel Arellano, 1999, "Symmetrically Normalized InstrumentalVariable Estimation Using Panel Data," Journal of Business and Economic Statistics, Vol. 17 (January), pp. 36-49.

Anderson, Roy, and Robert May, 1991, Infectious Diseases of Humans: Dynamics and Control (NewYork: Oxford University Press).

Arellano, Manuel, and Stephen Bond, 1991, "Some Tests of Specification for Panel Data: Monte Carlo Evidence and an Application to Employment Equations," Review of Economic Studies, Vol. 58 (April), pp. 277-97.

Arellano, Manuel, and Olympia Bover, 1995, "Another Look at the Instrumental Variable Estimation of Error-Component Models," Journal of Econometrics, Vol. 68 (July), pp. 29-51. 
Auerbach, Alan, Kevin Hassett, and Stephen Oliner, 1994, "Reassessing the Social Returns to Equipment Investment,” Quarterly Journal of Economics, Vol. 109 (August), pp. 789-802.

Azariadis, Costas, and Allan Drazen, 1990, "Threshold Externalities in Economic Development," Quarterly Journal of Economics, Vol. 105 (May), pp. 501-26.

Barro, Robert, and Jong-Wha Lee, 1993, "International Comparisons of Educational Attainment," Journal of Monetary Economics, Vol. 32 (December), pp. 363-94.

Blundell, Richard, and Stephen Bond, 1997, "Initial Conditions and Moment Restrictions in Dynamic Panel Data Models," Discussion Papers in Economics, No. 97-07 (London: Department of Economics, University College).

Calderón, César, Alberto Chong, and Norman Loayza (2002) "Determinants of Current Account Deficits in Developing Countries," Contributions to Macroeconomics, Vol. 2, No. 1, Article 2.

Calderón, César, Alberto Chong, and Luisa Zanforlin, 2001, "On Non-Linearities Between Exports of Manufactures and Economic Growth," Journal of Applied Economics, Vol. IV (November), pp. 279-311.

Chong, Alberto, and Luisa Zanforlin, 2001, "Technological Adaptation, Trade, and Growth," Weltwirtschaftliches Archiv, Vol. 4, pp. 565-92

Coe, David T., and Elhanan Helpman, 1995, “International R\&D Spillovers," European Economic Review, Vol. 39, No. 5, pp. 859-87.

Cooley, Thomas (ed.), 1995, Frontiers of Business Cycle Research (Princeton: Princeton University Press).

Creighton, Charles, 1965, History of Epidemics in Britain (London: Frank Cass).

David, Paul, 1990 "The Dynamo and the Computer: An Historical Perspective on the Modern Productivity Paradox," American Economic Review Papers and Proceedings, Vol. 80, pp. 355-61.

Davies, Stephen, 1979, The Diffusion of Process Innovations (Cambridge: Cambridge University Press).

De Long, Bradford, and Lawrence Summers, 1991, "Equipment Investment and Economic Growth," Quarterly Journal of Economics, Vol. 106, pp. 445-502.

_, 1993 , "How Strongly Do Developing Countries Benefit from Equipment Investment?" Journal of Monetary Economics, Vol. 32 (December), pp. 395-415.

Duncan, S.R., Susan Scott, and C.J. Duncan, 1993, "The Dynamics of Smallpox Epidemics in Britain, 1550-1800," Demography, Vol. 30 (August), pp. 405-24.

Frankel, Jeffrey, and David Romer, 1996, “Trade and Growth: An Empirical Investigation," NBER Working Paper No. 5476 (Cambridge, Massachusetts: National Bureau of Economic Research).

_ NBER Working Paper No. 5732 (Cambridge, Massachusetts: National Bureau of Economic Research).

Geoffard, Pierre-Yves, and Tomas Philipson, 1995, "The Empirical Content of Canonical Models of Infectious Diseases: The Proportional Hazard Specification," Biometrika, Vol. 82, No. 1, pp. 101-14.

— 1996, "Rational Epidemics and Their Public Control," International Economic Review, Vol. 37 (August), pp. 603-24.

Goldin, Claudia, and Lawrence Katz, 1998, "The Origins of Technology-Skill Complementarity," Quarterly Journal of Economics, Vol. 113 (August), pp. 693-732. 


\section{TECHNOLOGY AND EPIDEMICS}

Gomulka, Stanislaw, 1990, The Theory of Technological Change and Economic Growth (London: Routledge).

Griliches, Zvi, 1957 "Hybrid Corn: An Exploration in the Economics of Technological Change," Econometrica, Vol. 25, No. 4, pp. 501-22.

Guerrieri, Paolo, 1992, “Technological Trade and Competition: The Changing Positions of the United States, Japan, and Germany," in Linking Trade and Technology Policies: An International Comparison of the Policies of Industrialized Nations, ed. by Martha Harris and Gordon Moore (Washington, DC: National Academy Press).

Hansen, Lars P., 1982, "Large Sample Properties of Generalized Method of Moments Estimators," Econometrica, Vol. 50 (July), pp. 1029-54.

Harrison, Ann, 1996, "Openness and Growth: A Time-Series, Cross-Country Analysis for Developing Countries," Journal of Development Economics, Vol. 48 (March), pp. 419-47.

Holtz-Eakin, Douglas, Whitney Newey, and Harvey Rosen, 1988, "Estimating Vector Autoregressions with Panel Data," Econometrica, Vol. 56 (November), pp. 1371-95.

Kiviet, Ian F., 1995, “On Bias, Inconsistency, and Efficiency of Various Estimators in Dynamic Panel Data Models,” Journal of Econometrics, Vol. 68 (July), pp. 53-78.

Lee, Jong-Wha, 1995, "Capital Goods Imports and Long-Run Growth," Journal of Development Economics, Vol. 48 (October), pp. 91-110.

Levin, Andrew, and Lakshmi Raut, 1997, "Complementarities Between Exports and Human Capital in Economic Growth: Evidence from the Semi-Industrialized Countries," Economic Development and Cultural Change, Vol. 46 (October), pp. 155-74.

Patel, Pari, and Keith Pavitt, 1990, "The Nature, the Determinants, and Implications of Uneven Technological Development," in Science, Technology, and Free Trade, ed. by John De la Mothe and Louis Ducharme (New York: Pinter).

Philipson, Tomas, and Richard Posner, 1996, “The Economic Epidemiology of Crime," Journal of Law and Economics, Vol. 39 (October), pp. 405-33.

Razzell, Peter, 1977, The Conquest of Smallpox (Sussex, England: Caliban).

Rostow, W., 1960, The Stages of Economic Growth: A Non-Communist Manifesto (Cambridge, England: Cambridge University Press).

Soete, Luc, 1987, “The Impact of Technological Innovation on International Trade Patterns: The Evidence Reconsidered," Research Policy, Vol. 16 (August), pp. 101-30.

Summers, Robert, and Alan Heston, 1991, "The Penn World Tables (Mark 5.6): An Expanded Set of International Comparisons, 1950-1988," Quarterly Journal of Economics, Vol. 106 (May), pp. 327-68.

Temple, Jonathan, 1998, "Equipment Investment and the Solow Model," Oxford Economic Papers, Vol. 50 (January), pp. 39-62.

United Nations, 1997, The Impact of HIV and Sexual Health Education on the Sexual Behaviour of Young People: A Review, Joint United Nations Programme on AIDS (Geneva: United Nations).

— various years, International Trade Statistics Yearbook (New York: United Nations). , various years, Bulletin of Statistics on World Trade in Engineering Products (New York: United Nations).

World Bank, 1997, World Development Indicators (Washington: World Bank).

Ziliak, James, 1997, "Efficient Estimation with Panel Data When Instruments Are Predetermined: An Empirical Comparison of Moment-Condition Estimators," Journal of Business Economics and Statistics, Vol. 15 (July), pp. 419-31. 